\title{
Commodity Feminism Today: An Analysis of the "Always \#LikeAGirl" Campaign
}

\author{
Cristina Dans
}

Follow this and additional works at: https://researchrepository.wvu.edu/etd

\section{Recommended Citation}

Dans, Cristina, "Commodity Feminism Today: An Analysis of the "Always \#LikeAGirl" Campaign" (2018). Graduate Theses, Dissertations, and Problem Reports. 5434.

https://researchrepository.wvu.edu/etd/5434

This Thesis is protected by copyright and/or related rights. It has been brought to you by the The Research Repository @ WVU with permission from the rights-holder(s). You are free to use this Thesis in any way that is permitted by the copyright and related rights legislation that applies to your use. For other uses you must obtain permission from the rights-holder(s) directly, unless additional rights are indicated by a Creative Commons license in the record and/ or on the work itself. This Thesis has been accepted for inclusion in WVU Graduate Theses, Dissertations, and Problem Reports collection by an authorized administrator of The Research Repository @ WVU. For more information, please contact researchrepository@mail.wvu.edu. 
Commodity Feminism Today: An Analysis of the "Always \#LikeAGirl" Campaign

\author{
Cristina Dans \\ Thesis submitted to the Reed College of Media \\ at West Virginia University \\ in partial fulfillment of the requirements \\ for the degree of \\ Master of Science \\ in \\ Journalism
}

Steve Urbanski, Ph.D., Committee Chairperson

Tom Stewart, M.S.J.

Mary Kay McFarland, M.A.

Cari Carpenter, Ph.D., M.A.

Department of Journalism

Morgantown, West Virginia 2018

Keywords: Commodity Feminism, Always \#LikeAGirl Campaign, Effective Marketing Communication, Intersectional Feminism, Focus Group Methodology

Copyright 2018 Cristina Dans 


\section{Abstract \\ Commodity Feminism Today: An Analysis of the "Always \#LikeAGirl" Campaign}

Cristina Dans

This study examined the Procter \& Gamble Always \#LikeAGirl commercial video for aspects of commodity feminism as defined by Goldman, Heath and Smith in their 1991 journal article "Commodity Feminism." The purpose of this study was to explore the connection between the \#LikeAGirl commercial and its viewers. Through this exploration, the study aimed to find any feminist sign values and/or feminine visual signifiers identified in the Goldman et al. (1991) definition of commodity feminism. In addition, this study sought to explore audience connections (positive and/or effective) to identified aspects of commodity feminism in the video. The commercial video was analyzed for aspects of commodity feminism using an in-depth data analysis approach, followed by another qualitative method of measurement. Focus group research, the second method, was conducted using a convenience sample of 30 West Virginia University students. These groups were transcribed, analyzed and coded by the researcher using the Scissor-and-Sort Technique. Findings from this study indicated that feminist sign values were the only aspects of commodity feminism in this commercial video. These connected most effectively with focus group participants when messaging connected on first a negative emotional level, and then led to a positive solution suggested by the brand. This study contributes to the marketing communications field by yielding informative observations concerning persuasive communication tactics to connect with the personal values of the audience. 


\section{DEDICATION}

I would like to dedicate this thesis to my sister, Ariana Cristina Dans, who has been my best friend and most constant source of support in my life so far. I have always admired you, your strength, independence and resolve in life. You are my hero, my best friend, my worst enemy and the best big sister I could have ever wanted in life. Without you, I would not be the woman I am today. Thank you for all that you have done to support me in school, work and in life. 


\section{ACKNOWLEDGMENTS}

First and foremost, I would like to thank each member of my committee for helping me through the process of writing my master's thesis. Dr. Steve Urbanski, my committee chair, Professor Tom Stewart and Professor Mary Kay McFarland of the Reed College of Media at West Virginia University (WVU), as well as Dr. Cari Carpenter of the WVU Department of English and the WVU Center for Women's and Gender Studies, all guided me through the development of my thesis. Each member of my committee helped me along the way; all made themselves available to help me when I needed it and gave advice and suggestions to support me in my endeavors. I am so grateful for my committee and all that each of them have done in my research and writing process, as well as throughout my academic career at WVU thus far. Each of these professors inspired me in his or her own way, and gave me the encouragement I needed along the way.

I would like to especially thank Dr. Steve Urbanski, who has been my inspiration and mentor in my undergraduate and graduate school at WVU. Dr. Urbanski commits his time to his students above all else. His door was always open and he was always there to offer help, guidance, advice and general kindness and encouragement. Truly without the help of Dr. Urbanski, I do not believe that I would have been able to develop my thesis to this point.

Lastly, I would like to thank my family — specifically my Mami, Papi—my friends

and my loving boyfriend who have been there for me and forever supported me throughout my thesis-writing process. This has been a long and arduous journey that could not have happened without their endless love, patience and support.

Thank you, all of you, for all that you have done to help me tackle this beast! 


\section{TABLE OF CONTENTS}

Table of Contents

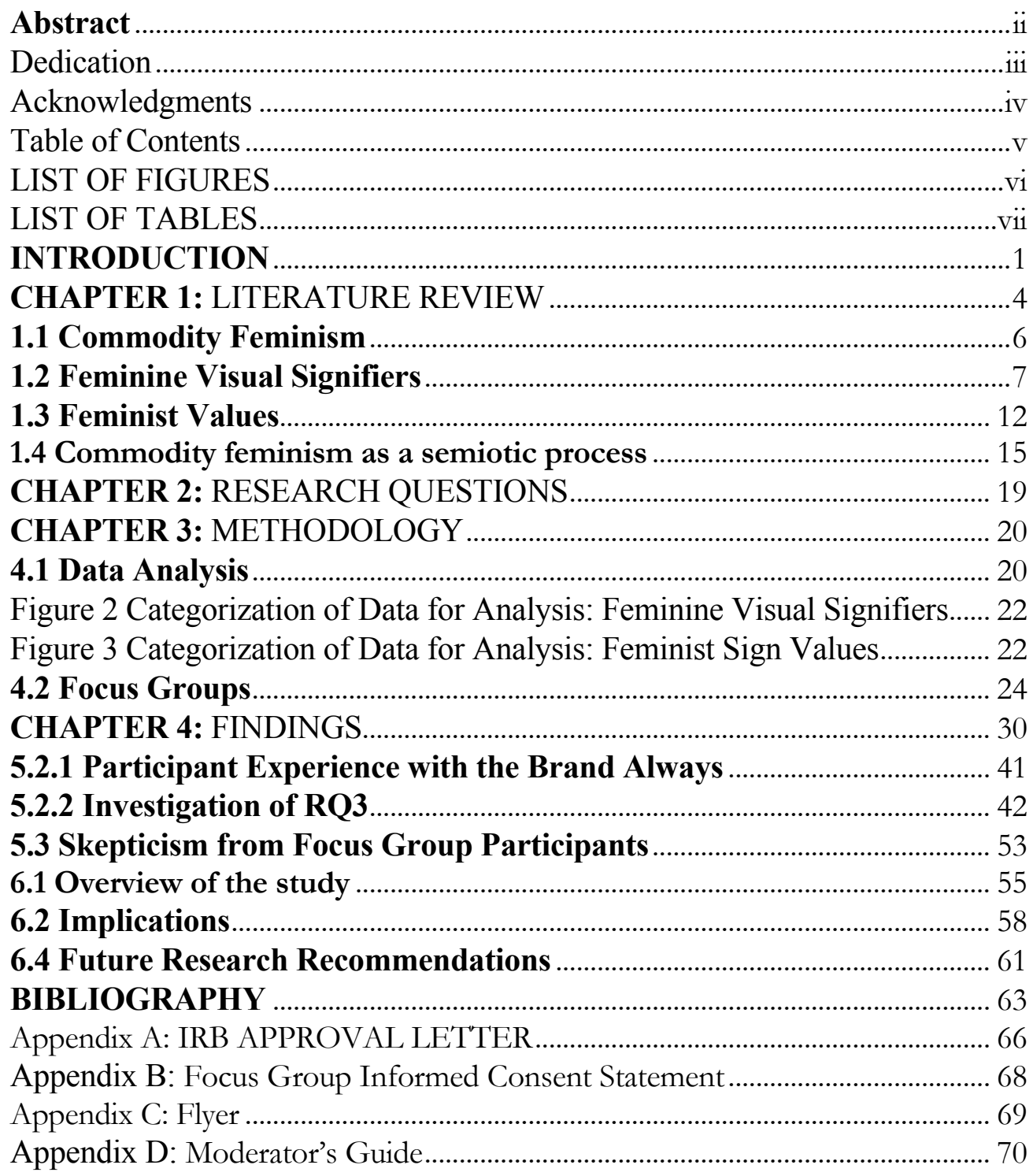




\section{LIST OF FIGURES}

Figure 1 Instagram Advertisement for Makeup.................................................10

Figure 2 Categorization of Data for Analysis: Feminine Visual Signifiers .....22

Figure 3 Categorization of Data for Analysis: Feminist Sign Values ...............22

Figure 4 Video Screen Cap A from Always (2014) \#LikeAGirl Video ............32

Figure 5 Video Screen Cap B from Always (2014) \#LikeAGirl Video.............33 


\section{LIST OF TABLES}

Table 1 Feminist Sign Values from Video Analysis ..........................................39 


\section{N T R O D U C T I O N}

It is not uncommon for contemporary advertisements to mirror current social movements/ideals within their messaging in order to connect with targeted consumer needs (Taylor, Johnston, \& Whitehead, 2016). In fact, much of modern advertising has "become a location for public discourse around meaning, social values, and corporate goals" (Pardun, 2013, p. 270). Advertising in the United States is often a reflection of societal interests, trends, values and norms, which are constantly changing. These frequent changes have consequences for advertisers; due to this factor, most advertisers and marketing researchers closely "monitor these changes and their impact on the ways companies market their products and services" (G. Belch \& M. Belch, 2014, p. 132). It is the goal of many advertisers to understand current consumer trends, interests and the "context in which consumer purchase decisions are made" in order to "adapt their advertising and promotional programs accordingly" (p. 132).

There have been several examples of this concerning recent advertising campaigns targeted toward women and their relevance to current social ideals/interests - particularly that of female empowerment. One example includes Procter \& Gamble's "Always \#LikeAGirl" campaign video which has received awards for its "female empowerment" and "feminist qualities" (Nudd, 2015). These awards include the "2015 Emmy Award for Outstanding Commercial," the 2014 Grand Clio Award and the 2015 Webby Award (Nudd, 2015). Additionally, the video has gone viral since its release on June 26, 2014, with more than 63 million views (Burnett, 2014).

In the aforementioned video, the brand Always attempts to communicate the importance of female empowerment and gender equality in American culture. The video illustrates the idea that describing a weak or uncoordinated action as being done "like a girl" is insulting to women and potentially damaging to prepubescent girls, as they are highly impressionable (Always, 2017). The underlying principle of this campaign message is to empower girls, increase their confidence levels and bring a positive new meaning to “doing things [like a girl]" (Always, 2017). 
This commercial was lauded by many news sources and female empowerment organizations as being an advertisement with positive "feminist" messages. One of these organizations is the American Association of University Women (AAUW). The AAUW describes itself as "the nation's leading voice promoting equity and education for women and girls," and was a major supporter of the "Always \#LikeAGirl" campaign (Imondi, 2016). On its website, the AAUW praised the video as one of the "best feminist superbowl commercials" for having "defied stereotypes about what it means to run, throw, or fight like a girl" (Imondi, 2016). This praise for the campaign video as being "feminist" and empowering to women is just one of many surrounding the advertisement.

Despite this praise, there was also a large amount of criticism from self-proclaimed feminist news sources and organizations. Andi Zeisler, editor and creative director of Bitch magazine, wrote about her doubt regarding the sincerity of the campaign in her recent book We Were Feminists Once. Zeisler considered the advertisement to fit into an area of female consumerism or commodity feminism which has been recently dubbed "Femvertising" or "Empowertising" in popular culture (Zeisler, 2016, p. 27). Zeisler also discussed in her book that, though feminist and empowering ideals are upheld within the video, the video itself is only marketing the empowerment of women for capitalist reasons and therefore should not be celebrated (Zeisler, 2016, p. 27).

These differing responses to the Always commercial lead to a few questions: Is this commercial, and others like it, a route for change with regard to the feminist movement? Or is it just a well-executed example of commodity feminism today? And, if this is commodity feminism, which aspects of the video exhibit commodity feminism? Which aspects connect most effectively with viewers? While the main message of this campaign boasted the empowerment of women, it is important to remember that the message is derived from a company whose primary goal is to sell a product. For this reason, one objective of this study was to ascertain whether this campaign exhibits aspects of commodity feminism. Another objective of this study aimed to explore the way viewers perceived this commercial - concerning either positive or negative emotional responses. The objectives of this study were of a theoretical nature, which aimed to use a differing scope to expand upon 
existing exploration of a similar commercial advertisement in a 2016 study by Taylor, et al. on the effects of the Dove Real Beauty Sketches Campaign. 


\section{CHA P T E R 1: L I T E R A T UR E R E VIE W}

As mentioned previously, an existing study with a similar framework of objectives examined the Dove "Real Beauty" campaign and utilized focus groups to explore whether corporations (like Dove) are possible routes for feminist change and if the Dove campaign was a "feminist" commercial (Taylor, et al., 2016). The authors suggested that classical critical theory (particularly that of Herbert Marcuse) was relatable to the material discussed within the experiment. This article was organized in a linear fashion based on the main topics of the study: an introduction with background information on consumption behavior and the "phenomenon of feminist consumption," background information on classical critical theory in relation to feminism and consumer culture, a methodology of the study, findings and a reflective conclusion (Taylor et al., 2016, p. 124).

Within the findings of this study, it was observed that many of the participants (self-identified feminists) were critical of the Dove campaign; they did not see the ad as feminist but as a way to draw consumer purchases. This is similar to the opinions of Ziesler, who attributed the majority of the messages to capitalist intent in "Femvertising" (Zeisler, 2016). However, the participants in this study also saw the campaign as a move in the "right direction" concerning female empowerment through "ethical consumption" (Taylor et al., 2016, p. 140). Additionally, participants opined that the use of corporations to promote feminist change is not a pragmatic action but that these types of promotions could "achieve social benefits" and lend a hand in the feminist movement (Taylor et al., 2016, p. 140).

The Dove "Real Beauty" campaign study served as part of the framework for this study, done instead from a marketing communications perspective. This new study was examined from certain parts of the Dove study — specifically a background/connecting factor of the frequent emergence of commodity feminism. However, these aspects were explored using the \#LikeAGirl campaign commercial (largely because it was lauded for having feminist content) and explored the relationship and effective communication with its intended audience. In addition, this study aimed to analyze the emotional responses and level of connection between the video's messaging and its audience. 
It is important to also note that Dove is a "product brand" owned by Unilever, a "large consumer goods company" (Fisher-Butting \& Vallaster, 2010, p. 27). Dove, as mentioned previously, is known for its ethically responsible advertising for showcasing women of a variety of shapes and sizes within its ads, in order to "boost self-confidence" in women (Fisher-Butting \& Vallaster, 2010, p. 27). Another well-known product brand owned by Unilever is Axe, "the number one male brand in the total antiperspirant/deodorant category" in 2007 (Lindström, 2012, p. 82). Axe's advertisements communicate that Axe deodorant is the "key to enhanced success with women - they would spray it on to boost their self-confidence" (Lindström, 2012, p. 81). Within the Axe commercial videos, when a man used the deodorant, a group of women immediately appeared alongside him, flocking to him because of the product (Lindström, 2012). These advertisements were lauded by many news sources for being "funny, brilliant, offensive, or outrageously sexist" and were also seen as proof that "sexism sells" (Lindström, 2012, p. $82)$.

Clearly these two product brands differ greatly in their messaging, despite the fact that they are shared by the same parent company: Unilever. This controversy in brand messaging has arisen as a large topic of debate within past years. In fact, as a result of the differences in campaign messaging, Unilever has been "accused of hypocrisy" (FisherButting \& Vallaster, 2010, p. 28). With the rise in discussion of the controversy of Unilever owning such different product brands, the consumer awareness of the connection between Axe and Dove has also increased. This has made it challenging for Unilever "to operate both brands credibly" in the eyes of the consumer, without the consumer simply seeing these ads as "just another marketing gimmick" (Fisher-Butting \& Vallaster, 2010, p. 28).

It is important to note this factor concerning the Dove and the Dove "Real Beauty" campaign as it shows the possibility of consumer awareness concerning advertisements. Some consumers in the Dove "Real Beauty" campaign study may have already been aware of the connection between Axe and Dove and felt that the campaign was simply a marketing tool because of their knowledge of this connection. It is also important to note this factor, as it feeds into the question from the study of whether this Dove "Real Beauty" 
campaign was an example of commodity feminism — as many believe it to be - or as a possible route for feminist change.

\subsection{Commodity Feminism}

What is commodity feminism? How has it been used in the past? What does it stem from? And how is it relevant in advertising today? Commodity feminism is a term that has been defined in previous research as "a corporate strategy that employs feminist themes of empowerment to market products to women," (Taylor, et al., 2016, p. 124). As this study aimed to explore the nature of the \#LikeAGirl commercial and the connection with its viewers through the marketing communications perspective of commodity feminism, it is important to first give background to the term: "commodity feminism." This subsection of the literature review gives background on the use of commodity feminism in past advertising, explores how the strategy works and examines where it stems from and discusses its relevance in today's advertising world.

In regard to commodity feminism in past advertising, an article by Rosalind Gill (2008) discusses the recent shift in advertising, which began empowering women through the scope of commodity feminism. Gill attributes the shift in advertising in the 1970s to "women's increasing financial independence"; this increase in buying power sparked advertisers' need to restructure message strategies to more effectively sell to the female audience (p. 39). Since this point, advertising has continued to change; in fact, by the "early 1990s, advertisers had begun to recognize the significance of women's anger at being objectified.... [They] started to rethink their engagement with female consumers and their ways of representing women" (Gill, 2008, p. 39). It was from this point that advertisers began to incorporate "the cultural power and energy of feminism" into messaging something that became known in the marketing communications field as "commodity feminism" (p. 39).

Now that a brief history of the term has been discussed, it is important to analyze it further to fully understand how it works and where it stems from. In another journal article titled "Commodity Feminism," advertisements, women's responses to them and “advertisers' methods of managing these responses" are closely examined through the lens of commodity feminism (Goldman, Heath, \& Smith, 1991, p. 332). This article highlighted 
the growing habit of reflecting identifiable values/ideals of feminism juxtaposed with visual signifiers associated with femininity within advertisements. Additionally, it highlighted the importance of the responses these advertisements yield from the female audience (for future strategies within the marketing communications field).

\subsection{Feminine Visual Signifiers}

Concerning the juxtaposition of feminism with femininity in advertising and the mass media, the article closely examined both and identified the visual signifiers/values associated with each. In reference to visual signifiers associated with femininity, those identified include the "emphasis of the lines and curvature of the female form, a "code of poses, gestures, body cants and gazes"” (Goldman et al., 1991, p. 348). These visual signifiers, symbols that detail the physical female form/outline, have become familiar through their association in the mass media with femininity. We have broken down the female body into "zones of consumption - lips, eyes, nails, hair, cheekbones, breasts, hips, waist, legs" (Goldman et al., 1991, p. 337). In this way, we are now so used to associating femininity with an intense segmentation of the female body that we "now accept the signifier, e.g. the [close-up] curve of a calf or the hip or an ear lobe, to stand for the feminine" (Goldman et al., 1991, p. 337).

In Western culture, femininity is visually distinct from masculinity due to these coded feminine visual signifiers like the outline of the female form, high heels and/or makeup. This is specifically in regard to the clothing associated with femininity, as is supported by this quote discussing a child looking at a picture of the Biblical Adam and Eve from Susan Brownmiller's (1984) book, Femininity:

When a child is asked by its parents whether the naked person in the picture is a man or a woman and the child replies, 'I can't tell because they're not wearing clothes,' the joke is really quite profound. In a clothed culture, the eye depends on artificial externals for its visual cues.... Skirts and pants stand juxtaposed as the Western world's symbolic great divide. A traveler who does not speak a word of a foreign language can locate the male or female restroom in an international airport by seeking out a recognizable logo, a painted stick figure with a triangular skirt leads unquestionably to the women's lounge (p. 82). 
Though this quote does not speak specifically to feminine visual signifiers within advertising, it does speak to the significance and universal understanding/recognition of these signifiers from all ages. The outline of the female form and the feminine clothing she wears are understood as feminine. This is how these signifiers are so clearly identified as feminine by advertisement viewers - advertisers utilize the major visual signifiers of femininity which truly set femininity apart from masculinity in a way that is universally recognized. Brownmiller also recognizes this "grouping of men in trousers and women in skirts [as] something akin to a natural order" in western society, as "basic to the covenant of masculine/feminine difference as the short hair/long hair proposition" of difference (Brownmiller, 1984, p. 83).

The societal acceptance of these feminine visual signifiers - specifically representations of the fragmentation of women's bodies in various types of media-is something that can be identified in both older and newer media. One particular example where this fragmentation is evident is the famous novel-turned-movie: Dracula, written by Bram Stoker in 1897 (Stoker, 1979). Within this novel, "a book whose fundamental anxiety, an equivocation about the relationship between desire and gender, repeats, with a monstrous difference, a pivotal anxiety of late Victorian culture" (Craft, 1984, p. 108). Specifically, the diary of Jonathan Harker in the novel describes the moment just before Harker is going to be kissed by "the incestuous vampiric daughters who share Castle Dracula with the count" (Craft, 1984, p. 108):

All three had brilliant white teeth, that shone like pearls against the ruby of their voluptuous lips. There was something about them that made me uneasy, some longing and at the same time some deadly fear. I felt in my heart a wicked, burning desire that they would kiss me with those red lips (Stoker, 1979, p. 51).

This quote, from the very beginning of the novel, immediately focuses on the lipsspecifically the red lips - of the women being described. These lips are what Harker is immediately attracted to, an immediate acceptance of the most feminine parts of the female form described in relevance to this longing and attraction he is feeling. This ties into the acceptance of the red lips as feminine - as a feminine visual signifier (Goldman et al., 
1991). This quote is not the only example of focus on lips within Dracula; in fact, the image of red lips is focused on repeatedly throughout the rest of the novel. As analyzed previously by Christopher Craft in his (1984) article: "Kiss Me with Those Red Lips," this quote exemplifies the "most sensational representation in the image of the Vampire Mouth, the central and recurring image of the novel" (Craft, 1984, p. 109).

The representation of these lips "as the primary site of erotic experience in Dracula" equivocates, giving lie to the easy separation of the masculine from the feminine" (Craft, 1984, p. 109). The image and focus on the lips throughout this story further exemplifies the accepted femininity of the image from the perspective of the novel. In addition, the image of the lips is accepted as erotic - desirable and attractive to the masculine in opposition to the feminine in this story. These aspects go hand-in-hand, further separating the masculinity from the red lips by use of the erotic nature ascribed to them initially by Harken in the novel (Craft, 1984).

This film has grown in popularity over time; many more books and movies have been produced on the topic of vampirism with the fragmentation and zoning in on the female form since Dracula was produced. The increasing popularity of this type of vampire film indicates the extensiveness of this representation of women's bodies in many types of media (Sanna, 2011). Instances of these signifiers of "femininity" and of the focus on lips are also found in current advertisements targeted toward women. One example of this is found within makeup advertisements: the figure below is an Instagram advertisement from tarte (2016), a makeup company, advertising "tarte lip paint:" 


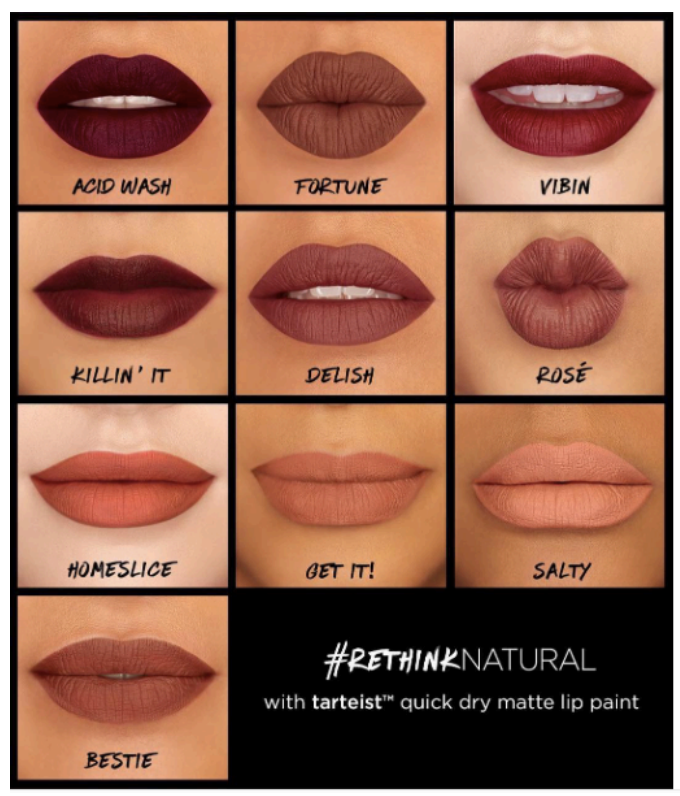

tarte tartecosmetics Following

tartecosmetics A quick dry, full coverage, transfer-proof liquid lipstick in 10 matte shades, without the icky bad stuff - YES, PLEASE! Check out our new tarteist quick dry matte lip paint with an ALL NEW FORMULA on tarte.com!!! \#RethinkNatural \#NaturalArtistry \#trippinwithtarte

load more comments

engmooha88 @queenstorm1 Woooow u love those matte colors like me?

queenstorm1 @engmooha88 yesss okhty msa I love these awi awi I love matte makeup awi

caylyncoops Is anyone else's really streaky and blotchy when applying

elliechorlton_@maddie_gill

laurachantriaux @alexyanidegger 98

alexianideqger @laurachantriaux ie

O

68,443 likes

OCTOBER 17, 201

Add a comment.

Figure 1 Instagram Advertisement for Makeup

This advertisement clearly exhibits one of the previously mentioned signifiers: multiple images of lips wearing the "tarteist lip paint" being advertised (tartecosmetics, 2016). It is important to note that, though this is an advertisement targeted toward women (the primary wearers of makeup) for lip paint, the physical product itself is not depicted. Only the lips wearing the lip paint are shown in the ad, yet the message is still clear concerning the product being advertised. These images of lips are one of the "zone[s] of consumption" associated with femininity; this is a segmentation of the female body to a very small and recognizable part, a part immediately accepted as feminine (Goldman et al., 1991, p. 337).

As has been discussed within this current advertisement and within the example of the significance of the red lips in Dracula, the segmentation of the lips is a prominently accepted visual signifier of femininity. In fact, the association of femininity, the fragmentation of the female body and cosmetics has been seen repeatedly throughout history (Brownmiller, 1984). This can be seen as early as 1940s Hollywood, a time in which famous actresses portrayed "an image of erotic femininity" associated with their red lips, manicured nails, "pancake makeup, false lashes, fake nails and matching lipstick and polish" (Brownmiller, 1984, p. 163). These advertised feminine aspects of the Hollywood 
actress made "the very words 'glamour' and 'glamorous' when applied to women become synonymous with the razzle dazzle of cosmetics glaze as much as with a curvaceous figure, high heels and revealing clothes" (Brownmiller, 1984, p. 163).

In addition to the Hollywood actresses in the 1940s, Susan Bordo mentions the fragmentation of the female body in the 1960s and 1970s in her (2013) book "Unbearable Weight: Feminism, Western Culture, and the Body." Here, Bordo discusses the "late 1960s and early $1970 \mathrm{~s}$ " as having "all the cultural paraphernalia of femininity...media imagery, beauty pageants, high heels, girdles, make-up ..." (Bordo, 2013, p. 182). This exemplifies the presence of these feminine visual signifiers as frequently occurring images during the 1960s and 1970s and continuing into today.

Another well-known example of these feminine visual signifiers can be found with the Barbie doll: a child's doll that is a plastic figurine of a woman. It is important to note here that, although the Barbie doll is meant to be a toy modeled after the female form, the doll's bodily dimensions are not at all proportional to those of the average female human being (Brownell, Napolitano, Mongrain, \& Van der Feen, 1995). In fact, in order to "attain the proportions" of a Barbie doll, a woman would have to increase her height by $40 \%$, her chest by $14.3 \%$ and decrease her waist by $21.4 \%$ (Brownell et al., 1997, p. 296). These are drastic changes which clearly show the unrealistic nature of the Barbie doll as compared to the actual female form, despite the fact that the Barbie is a well-known model of femininity (Mattel, 2009).

Since the first Barbie in 1959, this doll has been marketed as a "girl's" toy and has become a recognized symbol of femininity in association with the female form of the doll, along with variations of the brand's logo (Mattel, 2009, para. 5). One variation of the Barbie logo, an outline of a woman's head showing her long ponytail, eyelashes and lips, exemplifies this as one of the aforementioned signifiers considering its association of Barbie dolls with femininity, and marketed toward the female adolescent/infant audience. This outline of the female form is one which we immediately accept, understand and associate as something that is feminine and representative of femininity. Stemming from this, the Barbie doll is accepted as a feminine toy for female children. 


\subsection{Feminist Values}

Following from this, in reference to visual signifiers associated with femininity, Goldman et al. (1991) recognizes feminist values to include "self-definition, control over one's body and personal freedom...personal strength (physical or social) ... [and] selfacceptance" (p. 337). Advertisers use these values to signify feminism within advertisements today — what the article calls "commodity feminism;" this term "presents feminism as a style - a semiotic abstraction - a set of visual sign values that say who you are" (Goldman et al., 1991, p. 337).

The values/ideals in advertising and the mass media used to define feminism suggest "independence, participation in the work force, individual freedom, and selfcontrol" along with "confidence and attitude" (Goldman et al., 199, p. 348). These are all values mirrored within the core concepts of feminism from early feminists (radical feminists in the Women's Liberation Movement), along with the overlapping values within the many types of feminism. These core concepts include "Woman" as a category, "experience" and "personal politics" (Grant, 1993, p. 4). For the purpose of understanding the feminist signifiers adopted by commodity feminism, it is important to first expand upon the core concepts of feminism from which these signifiers are derived.

The category of Woman in the feminist movement concerns the idea that "women are oppressed not by virtue of their class or race, but simply by the fact of their womanhood," but that women are simply oppressed as women (Grant, 1993, p. 160). This oppressive nature of this category is also accepted by Christina Hughes (2002), who writes that when we say "women" we are unconsciously "using the reference point of man to derive our meanings" (p. 16).

Another major topic of feminism concerns the equality between men and women. It is important to note here that equality in feminist theory does not exactly refer to the identical treatment of men and women. This is a complex concept that varies across many types of feminisms. The general notion of equality shared by the many types of feminisms is to strive for women to be treated as equal to but different from the yardstick of masculinity. This equal treatment refers to equal opportunity with men which "[enables] all individuals in a society to have equal access to the same life chances such as education and 
employability" (Hughes, 2002, p. 38). The "different" treatment refers to the types of feminisms that believe women are indeed different from men and should therefore be valued equally instead of being treated the same (Hughes, 2002).

This "different" treatment followed from the idea that in striving for equal treatment to men, men must be the "normative" and the "goal to be achieved"; not all models of feminism agree: some believe that women should be valued for their differences (Hughes, 2002, p. 34). These feminists believe that equality means being able to choose a life of motherhood or a life of working like a man and have those choices equally valued (Hughes, 2002). Continuing from this, the category of Woman is one of the driving concepts of feminism, one which invokes the need for independence and difference from the category of men, while still driving for equality between men and women.

The experience of women is another core concept of feminism which goes hand-inhand with the core concept of personal politics. Early feminists used their personal experiences as a way to write about feminism, the oppression of women and the need for change. Experience was the only tool available to early feminists in attempting to prove that women were indeed oppressed, and that "the category of Woman existed" (Grant, 1993, p. 31). This was vitally important in order to create a common ground for women-if there was no common ground, then there was no "analytic value of the major foundational theory" (Grant, 1993, p. 31). It is important to note here that, though many types of feminisms agree that the oppression of women is universally experienced, not all women are the same. It is imperative to recognize the differences among women (race, culture, religion, socioeconomic status, etc.) in regard to this concept (Grant, 1993, p. 49). These differences are also ingrained in the "equal but different" treatment discussed earlier: women strive for "equal but different" treatment within the category of Woman and without (Grant, 1993, p. 140).

These personal experiences, used as the basis for feminist writing to provide evidence for the oppression of women, were thrust into the political realm. Once women used experiences as proof of their oppression, "it followed that female political oppression had to be charted where women experienced it: in their daily lives" (Grant, 1993, p. 37). Consequently, the "personal is political" became an expression used to "draw attention to 
the political meanings and imperatives that derive from women's everyday experiences of their personal and private lives" (Hughes, p. 152). In this way, the core concepts of feminism overlap to form the start of the feminist movement.

The feminist movement is defined by Hughes (2002), as: "a movement towards greater equality and freedom, to which particular feminists and feminisms contribute both positively and partially" (p. 193). It is a movement based upon the drive for independence, equal opportunity, higher self-worth, strength and with value placed on difference and motherhood for the category of Woman. Unsurprisingly, these concepts are mirrored by the Goldman et al. (1991) values of feminism in commodity feminism. This is because, as mentioned previously, these values; self-definition, control over one's body and personal freedom...personal strength (physical or social) ... self-acceptance ... confidence and attitude" reflect the core concepts of the feminist movement (Goldman et al., 199, p. 348).

It is important here to note that this study leans more toward the concepts and ideas behind intersectional feminism. Intersectional feminism is the idea that "all forms of oppression intersect and should be considered at those intersections" (Jensen, 2017, p. 17). This type of feminism takes the many different oppressions and experiences of women into consideration. It also identifies with the aforementioned "equal but different" treatment within the category of Women and without (Grant, 1993, p. 140). In other words, intersectional feminism examines the different experiences and oppressions of women in regard to other women and to men. Additionally, this type of feminism places equal value on women to men - arguing that women have the same capabilities as men and should therefore be treated equally (Tong \& Botts, 2009). It is important to note here that gynocentric feminism, unlike intersectional feminism, similarly places value on women and the different experiences and oppressions of women (Hekman, 2014). Gynocentric feminism "argues for the superiority of values embodied in the traditional female experience and rejects masculine values" (Hekman, 2014, p. 48). However, gynocentric feminism places more value on women than on men while intersectional feminism places equal value on women to men (Hekman, 2014). That said, although many other forms of feminism exist and have been examined concerning the core concepts of feminism 
reflected in commodity feminism, intersectional feminism identifies most with the structure of this study.

Now that we have discussed the signifiers/values associated with "feminism" and "femininity" in advertising, we understand the many similarities and differences between the two. This leads us to question why aspects of "femininity" are combined with those of "feminism" for the process of commodity feminism to work. According to Goldman et al. (1991), this process combines the meanings of feminism and femininity to compose distinguishable "commodity signs ... that will stand out and be recognized in crowded marketplaces" (p. 336). In other words, commodity feminism mirrors the general system of commodity relations: turning "the relations of acting subjects into relations between objects" (Goldman et al., 1991, p. 336).

Commodity feminism, therefore, is the process of commodifying feminist goals by juxtaposing the meanings of "feminine" and "feminist" to give the subsequent combined version recognizable and associable sign-value in the marketplace. This commodification of feminism "fetishizes" feminism; in this process, "feminism has been cooked to distill out a residue - an object: a look, a style" (Goldman et al., 1991, p. 336). So advertisements effectively commodifying feminism might lead consumers to believe that the purchase of a product leads to the acquisition of feminist values associated with that product (i.e. selfdefinition, freedom).

\subsection{Commodity feminism as a semiotic process}

As previously discussed, the terms "sign" and "signifiers" are used to describe the meaning of the aspects of commodity feminism as defined by Goldman et al (1991); these terms emerged from the theory of semiotics. For this reason, it is important to briefly review the meaning and origins of the theory of semiotics before delving further into this study. Semiotics is defined as "the study of sign processes (semiosis), or signification and communication, signs and symbols, and is usually divided into three branches: Semantics, Syntactics, and Pragmatics" (Hamel, 2011, p. vii). It is "the theory and analysis of signs and significations" which studies "the way that signs signify — in conventional literary texts and legal documents, or in advertisements and bodily conduct" (Lechte, 1994, p. 137). This study at its most basic core, and commodity feminism as a whole, is studying the way 
that the signs of feminism and feminist values signify in advertisements like the Always commercial video addressed within this study.

The theory of semiotics emerged from the theories of several noteworthy authors including Ferdinand de Saussure, Claude Levi-Strauss and Roland Barthes. Linguist Ferdinand de Saussure was considered by many to be "one of the fathers of modern semiotics" (Solomonick, 2015, p. 255). Saussure transformed modern linguistics through his 1916 Course in General Linguistics in which, as Solomonick wrote, "a language can be analyzed as a system of signs, and, because of this, it can be treated as part of the new branch of science he had conceived, which he called semiology (today's semiotics)" (Solomonick, 2015, p. 255). In fact, Saussure's statement that "language is the most complex and universal of all systems of expressions" came to later be known as the "primary semiotic principle" (Solomonick, 2015, p. 256).

Other noteworthy contributors to the theory of structuralism and, subsequently, the theory of semiotics were Claude Levi-Strauss and Roland Barthes. Levi-Strauss, a famous anthropologist and prominent contributor to structuralism, wrote the principle that "social and cultural life cannot be uniquely explained by a version of functionalism...nor can it be explained empirically by facts deemed to speak for themselves" (Lechte, 1994, p. 82). In addition to this, Levi-Strauss focused heavily on the aspect of "scope" within his contributions to structuralism, through his "universalist approach, [theorizing] on the basis of both his own and other anthropologists' data" (Lechte, 1994, p. 82).

Barthes, a famous semiotician, "views language modeled on Saussure's theory of the sign as the basis for understanding the structure of social and cultural life" (Lechte, 1994, p. 139). Barthes saw mythologies as more of a message than as a "concept, idea or object" (Lechte, 1994, p. 139). His work focused on the distribution of ideological views in media messaging. He studied how the media made advertisement images — signs communicate meaning in popular culture on a deeper level than what is found at first glance (Hamel, 2011). This ties in strongly with this study and examining the way in which aspects of commodity feminism — specifically concerning the Always \#LikeAGirl video - communicate meaning with its audience. 
This understanding of the process of commodity feminism and the origins of the semiotic theory behind it brings us back to the issue of whether it is a path for feminist change. Although distantly rooted in the core concepts of feminism, the fact remains that it is a strategy, which appropriates the goals of feminism with capitalist intent. Commodity feminism is not a path for feminist change but a de-politicization of feminist goals into personal style (Rapp, 1988). This finding is reflected both within Gill's research and within Johnston and Taylor's research.

The strategy is not significant because it is a sign of advertisements becoming feminist, but because is an effective way to connect with the intended audience through feminist ideals (Gill, 2008). How, then, is it effective? Goldman et al. (1991) state that the "market motivated" process and "the commodity self that emerges from the totality of advertisements is the flip side of demographic profiles and the selling of audience segments" (p. 333). Commodity feminism effectively reflects the needs and desires of the intended audience in order to connect with them. In addition, Judith Williamson (1978) argues that an advertisement's meaning and effectiveness rely on the level of involvement from the consumer - without consumer participation, "an ad cannot produce a sign that possesses value within a currency system" (p. 40). It follows that an advertisement using commodity feminism is effective if its message catches the attention of its audience and connects with them on a personal level.

"Commodity feminism" has become a key part of advertising tactics today. The real-life example discussed previously (the Dove advertisement) exemplifies this point. Advertisers have continued attempting to reflect the values of feminism within marketing communications, listening to the feminist consumer in order to fine-tune strategies. These strategies are used to create advertisements which connect with the intended audience and encourage positive connection and buying behavior. However, these advertisements do not explicitly show which values/signifiers used in the strategy connect most effectively with the intended audience. This leads us to wonder about how commodity feminism is used in today's advertisements - specifically in advertisements lauded for being "feminist" like the \#LikeAGirl commercial discussed earlier. 
Many of the feminist values touted in Always' official website description of the "Like A Girl" campaign are congruent with the sign values/signifiers associated with commodity feminism discussed within the Goldman et al. (1991) article. For example, Always' description of doing things "\#LikeAGirl” includes helping girls and women to maintain their confidence "throughout puberty and beyond" (Always, 2017). Additionally, the video content encourages strength and self-acceptance within girls and women: "I am a girl, and that's not something that I should be ashamed of" (Burnett, 2014). Due to this overlapping of feminist values within the video and research and the celebration of this commercial campaign as being "empowering to females" and "feminist," this campaign is an excellent topic of exploration within this study.

This study analyzed this advertisement to find and highlight any feminist values/feminine visual signifiers identified in the Goldman et al. (1991) definition of commodity feminism. After sorting these from the advertisement, the feminist values/feminine visual signifiers were assigned as either "feminine" or "feminist" in order to get an idea of the ratio used in today's advertising. Then these feminist values/feminine visual signifiers were utilized to determine whether respondents identify them within the commercial content and, if so, whether these create a positive or negative emotional connection with the respondents. 


\section{CHAPTER 2: RESEARCH QUESTIONS}

In reflection of this literary analysis, it can be assumed that the marketing communications field utilizes the strategy of commodity feminism: appealing to the female consumer based upon feminist ideals and values. However, the feminist values/feminine visual signifiers that most effectively connect with today's intended consumer remain to be seen. Additionally, the feminist values/feminine visual signifiers which connect most positively with the intended consumer audience (women specifically) remain to be seen. Based upon these queries, the following research questions were explored:

RQ1: Does this video communicate any of the feminist values/feminine visual signifiers of commodity feminism as defined by Goldman?

RQ2: Are the majority of these feminist values/feminine visual signifiers associated with femininity or with feminism?

RQ3: Which feminist values/feminine visual signifiers of commodity feminism within this video communicated positively with the audience?

RQ4: Which feminist values/feminine visual signifiers of commodity feminism connected most effectively with the audience? 


\section{H A P T E R 3: M E TH O D OL O G Y}

In order to answer these research questions and fully understand the topics and objectives under investigation, two qualitative methods of research were conducted. These two methods of measurement were: 1) A data analysis of the \#LikeAGirl commercial video, followed by 2) focus groups based on the findings from the previous method of measurement. Rationale behind these methods of measurement, along with the full data analysis, will be explained in the following paragraphs.

\subsection{Data Analysis}

Prior to focus group measurement, a detailed data analysis of the \#LikeAGirl commercial was done based on the feminist values/feminine visual signifiers discussed in the literature review. A data analysis is a form of analysis done early in research which "continues throughout the project" (Wimmer \& Dominick, 2014, p. 119). This is an inductive method in which "data are collected relevant to some topic and are grouped into appropriate and meaningful categories; explanations emerge from data" (p. 119). This method of measurement was especially useful in this study, as it is often used by researchers to "investigate the transferability of another author's ideas to a different social context" (Daymon \& Holloway, 2010, p. 303).

This particular video analysis was completed following the regular structure of organizing the data in analysis and coding each piece of information in the data set, along with including a transcription of events in the data (here, in the video) (Wimmer \& Dominick, 2014). This data organization was prepared prior to the investigation/official analysis of the video because "the researcher is the main instrument in qualitative data collection and analysis and therefore must prepare before beginning the task of investigation" (p. 119). The preparation for this analysis included going through the process of epoche. Here, epoche was defined as the process of the researcher removing bias and becoming fully objective or "at least aware of prejudices, viewpoints, or assumptions that might interfere with analysis" (p. 119). This process was largely completed by acknowledging personal perspectives/opinions of aspects of the study, taking major themes 
of the literature review into consideration and coming up with a code of categorization to analyze transcriptions with and help to separate possible bias from investigative analysis. A code, or "label that represents an idea or a phenomenon," assists in condensing and summarizing "the evidence in order to begin to make sense of it" (Daymon \& Holloway, 2010, p. 306). The structure for the categorization of data for analysis within this research was as follows:

This stage of analysis followed the first step of the constant comparative technique recommended by Wimmer and Dominick (2014) in their book Mass Media Research: "comparative assignment of incidents to categories" (p. 120). This step included the process of categorizing the data in analysis. For this, the feminist values/feminine visual signifiers were grouped into two tables, based upon whether they align with the feminine (those in Figure 2) or feminist (those in Figure 3) of the feminist values/feminine visual signifiers discussed in the literature review. 


\begin{tabular}{|r|}
\hline \multicolumn{2}{|c|}{ Feminine Visual Signifiers } \\
\hline $\begin{array}{l}\text { 1. } \\
\text { Emphasis of lines/curvature of the female form. } \\
\text { (i.e. outline of the female body/parts of the female } \\
\text { body). }\end{array}$ \\
\hline 2. Code of poses, gestures, body cants, crossed legs. \\
\hline 3. Gazes \\
\hline 4. \\
$\begin{array}{l}\text { Lips, eyes, nails, hair, cheekbones, breasts, hips, } \\
\text { waist, legs (i.e. close-up curve of a calf), earlobe } \\
\text { (with earring). }\end{array}$
\end{tabular}

Figure 2 Categorization of Data for Analysis: Feminine Visual Signifiers

\begin{tabular}{|c|}
\hline Feminist Values \\
\hline 1. Independence \\
\hline 2. Participation in the work force \\
\hline 3. Individual freedom \\
\hline 4. Self-control \\
\hline 5. Confidence \\
\hline 6. Attitude \\
\hline $\begin{array}{l}\text { 7. Diversity among women (in regard to culture, } \\
\text { ethnicity, skin tone, religion, etc.) }\end{array}$ \\
\hline 8. Oppressed as women \\
\hline $\begin{array}{l}\text { 9. Equality: Emphasis on the need for women to } \\
\text { be treated "equal but different" to men. } \\
\text { (Valued equally) }\end{array}$ \\
\hline $\begin{array}{l}\text { 10. Equality: Emphasis on the need for women to } \\
\text { be treated "equal but different" to other } \\
\text { women }\end{array}$ \\
\hline 11. Choice \\
\hline 12. Need for change \\
\hline 13. Emphasis on the need for higher self-worth \\
\hline
\end{tabular}

Figure 3 Categorization of Data for Analysis: Feminist Sign Values

The purpose of this analysis was to extricate, highlight, and analyze further any sign feminist values/feminine visual signifiers communicated within the video to aid in answering the first two research questions and in preparing the framework for the next method of qualitative measurement. Any feminist values/feminine visual signifiers identified within the messaging of the video were logged with their time stamp within the video, a photograph of that point within the video, a transcription of the dialog within that 
point and an analysis of that point as compared to the gathered information from the literary review. Through these measures, all of the feminist values/feminine visual signifiers found were highlighted, analyzed, categorized into the categories of feminist or feminine or both (if there was an overlap) and then rationalized for their categorization.

This stage of analysis followed the second and third steps of the constant comparative technique recommended by Wimmer and Dominick (2014): "elaboration and refinement of categories" and "searching for relationships and themes among categories" (p. 120). In the second step, the researcher rationalized the inclusion of a category after analysis and described the principal meaning of that category within the context of the data. This was done in the video analysis when each categorization applied within the data was rationalized and defined according to the context of the commercial message, the literature review and its relevance to the research topic. These rationalizations also pointed to the intended outcome of the categorized value in the data; ergo, the intention of including specific feminist values/feminine visual signifiers within the commercial.

In the third step, the researcher closely examined the statements/categories and looked for "meaning connections" in each (Wimmer \& Dominick, 2014, p. 121). This was done in the video analysis as well. Rationalizations pointed to the underlying message of the commercial campaign: acting/joining the brand Always in changing the perception of the oppressive "Like a Girl" phrase.

This analysis aided in supplying answers for RQ1 and RQ2: informing the research concerning the presence of these feminist values/feminine visual signifiers within the video as well as the type of feminist values/feminine visual signifiers. Furthermore, this analysis was used to determine whether or not there is a majority distribution of one type of feminist value/feminine visual signifier, an even mix or little to no presence within the video messaging. This information was important in formulating the next stage of research: investigating RQ3 and RQ4 concerning the type of connection feminist values/feminine visual signifiers of commodity feminism in advertising have with viewers (be it positive or negative) along with the effectiveness of that connection.

Effective connection with the consumer, for the purpose of this research, was operationally defined in marketing advertising terms as a way of engaging the consumer on 
an emotional level which "adds value to their lives" and "inspires" consumers to take action (Joseph, 2010, p. 90). This type of connection engages an audience in a "brand even though they don't need it" (p. 91). Action here refers to leading a consumer to become more aware of the brand, buy the brand's products, write a good review about the brand, post the hashtag on social media, post about the commercial/brand on social media and/or tell others about the brand/brand messaging. Action also refers to whether the connection led consumers to share/like/comment on the video on social media, feel differently about the brand - humanize the brand in any way, follow the brand on social media, feel differently/think about the phrase "like a girl" (the brand message) and/or to change their behavior concerning the phrase.

This marketing communications definition of effective connection/communication with a consumer was used because this research was done through the marketing perspective. It should be noted, however, that in future research on this topic, other perspectives/definitions of effective could be explored as an extension of this research. Following from this video analysis, another qualitative method of measurement was utilized in order to investigate RQ3 and RQ4.

Answering these first two research questions via the information found in the video analysis was an important step toward executing the next stage of research. This next stage investigated RQ3 and RQ4 concerning the type of connection signifiers of commodity feminism in advertising have with viewers (be it positive or negative) along with the effectiveness of that connection. Investigation of RQ3 and RQ4 was continued in this research using the second qualitative method of investigation discussed next.

\subsection{Focus Groups}

The second qualitative method for answering these research questions was moderator-guided focus groups; the moderator's guide that was formulated for these focus groups emerged from the information gathered from the video analysis. Focus groups were used as a method of measurement within this research because this strategy is used to "understand people's attitudes and behavior" which was necessary to answer the research questions within this study (Wimmer \& Dominick, 2014, p. 136). Along with this 
reasoning, focus groups allow for "flexibility in question design and follow-up" questions, which was necessary to gain detail in participant answers. In addition, this was the same method utilized within the 2016 Dove "Real Beauty" campaign study by Taylor et al. within their research of a similar framework.

For this research, focus groups were used to explore the connection between the respondents and the video messaging. More specifically, focus groups were used to explore the emotional connection (positive or negative) between the respondents and the feminist values highlighted from the data analysis of the commercial video. And, focus groups were used to observe the effectiveness of that connection (operationally defined on page 32) in regard to whether viewers were/are inspired to take action or if their behavior was changed after exposure to the video message and content.

These focus groups were fairly standardized; in all focus groups, a "fixed set of questions" were used by the moderator with only small amounts of variation for follow-up questions (Morgan, 1996, p. 142). Standardization in focus groups is "a matter of degree, and even standardized designs allow minor variations that accommodate the unique aspects of each group" (Morgan, 1996, p. 142). That said, certain follow-up questions were asked in addition to the fixed moderator's guide used for the focus groups — the full moderator's guide may be found in the appendices of this thesis. The reason for the standardization of these focus groups is for the advantage of a "high level of comparability across groups" which is important and highly valuable for analyzing group responses (Morgan, 1996, p. 142).

These groups were also more structured with regard to the moderator's involvement in the focus group dynamic. "More structured" here refers to the moderator "[exercising] a higher degree of control" during the focus group discussion using the fixed questions and follow-up questions in order to keep the group members on topic (Morgan, 1996, p. 145). In addition to this, these groups were "more structured" in that the moderator guided the participant exchanges; this was done in order to encourage "equal exchanges" within the focus group discussion (Morgan, 1996, p. 146). According to Morgan (1996), this high level of involvement and structure is the preferred method for marketing researchers concerning focus groups to help maintain the "group dynamic" (p. 145.) 
As for the size and frequency of the focus groups, a pretest focus group and two 45to 60-minute focus groups were conducted. The pretest focus group was conducted prior to the actual focus groups in order to hone in on questions and clear up any confusion or ambiguous questions before actual testing (Carson et al., 2001). For this pretest, a focus group was conducted using a convenience sample of 13 female WVU students between the ages of 18 and 27 in Martin Hall on the WVU downtown campus. This sample range was selected because of its similarity to the actual sample proposed for the overall focus group study.

The pretest yielded information preparing the researcher for themes to be expected to arise in other focus groups but did not show any questions were unclear or difficult to understand by participants; therefore, none of the questions from the moderator's guide were altered for focus groups 1 and 2. In addition, because the themes and discussions which arose among focus groups 1,2 and the pretest were all exceedingly similar and the groups were conducted in the same way and using the same type of sample, the researcher included the transcription and notes from pretest in analysis. The pretest, throughout the analysis and in the "Findings" chapter of this research, was therefore referred to and coded as focus group 3 .

These focus groups were conducted until saturation was achieved in terms of the recurring themes and topics of discussion between focus groups. Based on the recurring topics of discussion, the researcher did not believe that any additional information from this sample type would "generate new understanding" for this study (Liamputtong, 2011, p. 45). Saturation is operationally defined as something that "occurs when the focus groups no longer provide any fresh information" - this is something that is determined by the researcher based on the time, money, information needed and resources (p. 136). A total of 30 participants (seven in focus group 1, 10 in focus group 2, and 13 in focus group 3) made up the focus group sample. The number of participants in these focus groups was in accordance with the average range of participants in focus group research (6-20 participants per group depending on the study). There is "no consensus in the literature as to the number of participants in each focus group" although larger groups should be avoided so as to 
allow all participants the "opportunity to share insights and observations" (Carson, Gilmore, Perry, \& Gronhaug, 2001, p. 119).

The sample drawn for this study was a convenience sample of male and female West Virginia University students between the ages of 18 and 27 (which included both undergraduate and graduate age groups). The rationale behind using of both male and female participants within this study was in relation to the use of both males and females in the \#LikeAGirl commercial video, the intersectional feminist lens through which this study was completed and the feminist values reflected in commodity feminism. As mentioned within the literature review, the core concepts of feminism (as well as intersectional feminism) value the differences (among other women and between men and women). Additionally, the feminist values in commodity feminism include the need for equality and equal opportunity between men and women. In order to consider the presence of the feminist value of the need for equality between men and women, and the value on difference between the two, it was necessary to include both within this study.

This sample was recruited via flyer advertisements - approved by the Institutional Review Board (IRB) at West Virginia University — with incentives including extra credit opportunities. Only one of these focus group participants (a female participant in focus group 2) was a graduate student and international student; the rest of the participants were undergraduate American students. This convenience sample yielded mostly female participants (three males and 27 females in sample). The average age of the focus group participants was 19.8 years. The average age of participants in focus group 1 was 19.14 years, the average age of those in focus group 2 was 19.4 years and the average age of those in focus group 3 was 20.46 years.

The fact that this convenience sample yielded participants of similar ages and shared status as West Virginia University students was beneficial in terms of the homogeneity of the overall sample. Homogeneity concerning shared experiences is an important factor of a good focus group. This is because participants with "similar lived experiences are more likely to talk openly with each other" and feel comfortable in the discussion (Liamputtong, 2011, p. 36). Having homogeneous group participants produced rich and in-depth information concerning the shared experiences of the participants during 
focus group discussion and brought about important recurring themes in analysis which overlapped among groups.

Each focus group was executed using standard focus group procedure: The researcher acted as the moderator, leading each discussion using a moderator's guide designed to gather data relevant to the research topics under study. It is very common for the researcher to act as the moderator in academic research involving focus groups; this is largely because the primary researcher is most familiar with the topics being explored in focus group discussion. In addition to this, the researcher acting as moderator is "able to put all comments into perspective and follow up critical areas" during focus groups (Carson et al., 2001, p. 121). The two actual focus groups were held on the West Virginia University (WVU) downtown campus at the WVU Wise Library in reserved and private library rooms. Focus group 3 (the pretest focus group) was held on the WVU downtown campus in a classroom in Martin Hall.

Audio of each group was recorded for later evaluation, transcription and information analysis. The transcription of each focus group was completed by the researcher for analysis. Included in the transcription were the moderator's notes taken during focus group discussion concerning the "nonverbal communication, gestures, and behavioral responses" which are important in drawing conclusions from emerging themes and patterns in focus group analysis (Stewart, Shamdasani, \& Rook, 2007, p. 110). However, for the purpose of keeping the identities of the participants private, the visual footage and any identifiers from the audio recordings were deleted from the final analysis for this research. Any names or demographic information (other than age and gender) were omitted from the findings of this research in order to maintain the privacy of each focus group participant. In place of names, the analysis of the information gathered during the focus groups included pseudonyms only representative of the self-identified gender of each participant. These steps comply with the focus group requirements of the guidelines set by IRB, under which focus group research must be submitted.

For the analysis of the focus group data, the "Scissor-and-Sort Technique" was conducted; this is a type of analysis used with focus group research (Stewart et al. 2007, p. 116). This is an effective analytical approach in which the "analyst determines which 
segments of the transcript are important, develops a categorization system for the topics discussed by the group, selects representative statements regarding these topics from the transcript, and develops an interpretation of what it all means" (Stewart et al. 2007, p. 116). In accordance with this technique, RQ3 and RQ4 were named the major categories from which subcategories of "Positive Connection," "Negative Connection," "Effective," "Feminist Sign Value" and "Feminine Visual Signifier" were developed as "representative statements" (Stewart et al. 2007, p. 116). These words/phrases, along with color coding techniques assigned to each research question, were used to code the transcripts and interpret meaning from the data. It is important to note that, although these were the categories and subcategories for analysis, the researcher was prepared for and aware of outside themes important to the study which were likely to arise throughout analysis (Stewart et al. 2007).

This analysis involved several stages of reading through, categorizing and interpreting meaning from the transcripts. After the materials were coded, and additional themes highlighted, the coded materials were sorted and matched to a major category based upon their relevance to RQ3 and RQ4. Each coded material was rationalized as to why it was relevant to its parent categories (RQ3, RQ4, both, or neither) and meaning was interpreted from the match or lack thereof. This analysis was completed by digitally coding materials to sort them and then printing and cutting apart the coded materials in order to categorize them further. This Scissor and Sort technique sometimes involves printing and cutting apart the coded materials in order to sort them, though effective analysis can result from the digital sorting and coding as well (Stewart et al. 2007). 


\section{H A P T E R 4: F I N D I N G S}

The following section is a discussion of the major findings of the previously mentioned methods of qualitative measurement in reference to the research questions. The first section delves into the data analysis of the commercial video, highlights the major findings of the analysis, and attempts to provide answers to RQ1 and RQ2. As previously stated, RQ1 explores whether any of the feminist sign values/feminine visual signifiers of commodity feminism as defined by Goldman are present in the commercial video. RQ2 emerged from this, attempting to find out if the majority of these feminist sign values/feminine visual signifiers (if there were any present in the video) were more associated with femininity or feminism. Following from this, the second section of this chapter identifies the major findings and themes which arose from the analysis of the focus group data, and attempts to provide answers to RQ3 and RQ4.

\subsection{Data Analysis Findings}

For this video analysis, the first commercial video (discussed in the literature review) of the Always Campaign: Our Epic Battle \#LikeAGirl was examined for the feminist values/feminine visual signifiers mentioned in section 4.1 of the methodology. The analysis was done in linear fashion, following the narrative of the video and including notes throughout the course of the video. This three-minute and 18-second video is titled: "\#LikeAGirl: How it All Started."

The purpose of this commercial video was for Always to improve communications and increase brand awareness with a "fresh and more meaningful understanding of confidence which could resonate with the next generation of consumers" (D\&AD, 2015, para. 1). This campaign, as a whole, was made to "leverage the brand's legacy of supporting girls" during development, reinforce the brand image, optimize brand perception, change the derogatory meaning of the phrase and "understand the social issues girls face today at puberty" (D\&AD, 2015, para. 4). In order to execute this plan, Always partnered with director and documentarian Lauren Greenfield (Always, 2014). Greenfield partnered with Always and made this video "to shed light on how this simple phrase can 
have a significant and long-lasting impact on girls and women ... [and] to be a part of the

movement to redefine 'like a girl' into a positive affirmation”' (Always, 2014). These points concerning the making of the video are important to note, as they emphasize that the main messaging and purpose of the video are largely in line with the feminist values mentioned in the literature review and within Figure 3. The purpose of the video campaign messaging includes the promotion of the feminist values of confidence, emphasis on the need for higher self-worth in women, recognition of the oppression of women (concerning the derogatory meaning behind the phrase "like a girl") and a need for change (changing the negative meaning of the phrase to a positive meaning).

\subsubsection{Video Summary}

Throughout the course of the video, Greenfield individually interviews a mix of male and female participants concerning their perceptions of the phrase "like a girl;" this interview footage has been compiled together. The video footage shows Greenfield first interviewing a group of post-pubescent (adults and teenage) participants (two Caucasian males, two Caucasian females and one African-American female), asking them to perform how they do something "like a girl." Then, the video footage shows these participants enacting what their first instincts are concerning what it means to run, fight and throw "like a girl." She later questions pre-pubescent females (five females, 10 years old and younger), asking them to perform the same actions as the older group in order to show the difference in how the phrase is perceived after puberty. Following from this, the video explores the major topics of the phrase as "an insult," how the phrase can negatively affect girl's confidence when it "plummets during puberty" and how Always wants to change the negative association with this phrase (Always, 2014). The following subsections highlight and summarize the major findings of this video analysis in association with the previously mentioned main topics discussed in the video.

\subsubsection{What does it mean to do something "like a girl?"}

Four seconds into the video, the question: "WHAT DOES IT MEAN TO DO SOMETHING 'LIKE A GIRL'?’ appears on-screen before Greenfield begins asking the participants this same question (Always, 2014). This question refers to the stereotypical phrase of "doing something like a girl" which implies doing something "girlishly"; defined 
by Alice Walker, to be "girlish" is to be "frivolous, irresponsible, not serious" (LaGrone, 2009, p. 258).

This exemplifies that the phrase "doing something like a girl," or doing something the way a female would do it, has oppressive meaning. It is akin to saying that the female way of doing something is less accurate or serious than the male way of doing something. Due to this analysis, this portion of the video was coded as feminist. This is a feminist value that is being communicated as a major brand message. It aligns with the following feminist values in Figure 3: 8. Oppressed as women and 9. Equality (or lack thereof) between the perception/value of male and female ability.

Greenfield then asks the older participants to perform how they do something "like a girl." Then, the video footage shows these participants enacting what their first instincts are to run, fight and throw "like a girl." Participants exaggerate actions in their performances of "like a girl," flail their arms, smile, act silly, giggle, comment about their hair getting messed up, etc. (Always, 2014).

These physical responses align with the previously mentioned definition of girlish; they exemplify frivolity and lack of seriousness. In addition, these responses show that

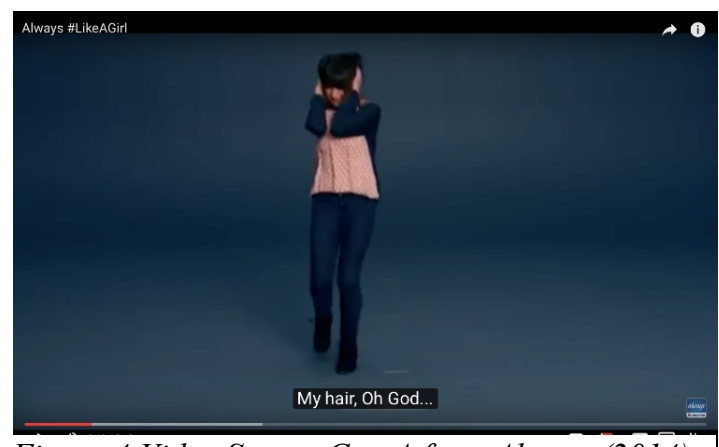

Figure 4 Video Screen Cap A from Always (2014), \#LikeAGirl Video the oppressive meaning of the phrase "like a girl" exists in American culture today. The actions used to perform "like a girl" by the older participants within this video associate the phrase with weakness and inability. For example, in one instance the younger of the two male participants even pretends to drop the ball when throwing "like a girl" and says:

"aww," in a disappointed tone (Always, 2015). These responses show that the preconceived notion of running/fighting/throwing "like a girl" means not running/fighting/throwing well or in seriousness.

Due to this analysis, this portion of the video was coded as feminist. These are feminist values that are being communicated and exemplified by the participants. This portion of the video aligns with the following feminist values in Figure 3: 8. Oppressed as 
women and 9. Equality (or lack thereof) between the perception/value of male and female ability.

Following from this, 38 seconds into the video, "WE ASKED YOUNG GIRLS THE SAME QUESTION" appeared on-screen before Greenfield begins asking the younger participants the same question (Always, 2014). This group of younger participants are all females and consist of four Caucasian females and one African-American female. When Greenfield asks them to run/throw/fight "like a girl," these participants ran/fought/threw with strength, assuredness, seriousness and intensity. No smiles or giggling were seen while the participants were showing what it meant to do these things "like a girl."

In addition to performing what it means to do something "like a girl," Greenfield asked a younger participant: "What does it mean to you when I say 'run like a girl'?"

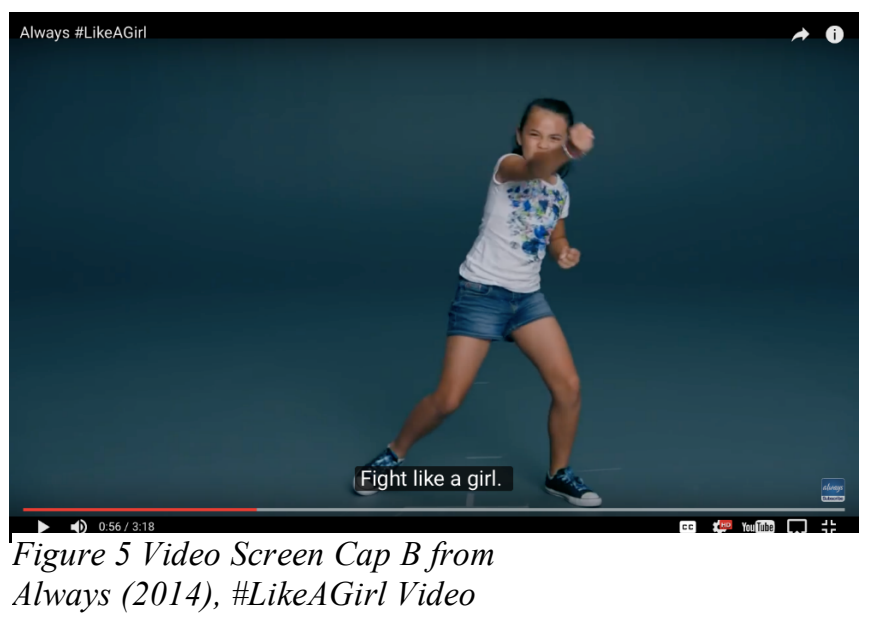

(Always, 2014). This participant answered: "It means [to] run as fast as I can," showing that the participant is aware and confident about her strength and ability (Always, 2014). These responses do not align with the definition of "girlish;" they exemplify confidence and high self-worth. Due to this analysis, this portion of the video was coded as feminist. These are feminist values that are being communicated and exemplified by the participants. This portion of the video aligns with the following feminist values in Figure 3: 5. Confidence and 13. Higher self-worth.

The difference in responses between the older and younger participants in this video also show that the oppressive meaning of the phrase "like a girl" is not perceived the same by prepubescent females in American culture today as it is by postpubescent males/females and the prepubescent boys. The side-by-side comparison of these differing perceptions of the phrase is meant to emphasize this difference in order to bring it to the attention of the viewer. This carries into the next main topic of discussion within the video. 


\subsubsection{When did doing something "like a girl" become an insult?}

One minute and five seconds into the video, the question: "WHEN DID DOING SOMETHING ‘LIKE A GIRL' BECOME AN INSULT?” appears on-screen before Greenfield begins asking the participants this same question (Always, 2014). This question implies that the brand recognizes the oppressive meaning behind the phrase "like a girl" and is supporting the idea that there is a need for change, that it is important for women to have higher self-worth and that men and women should be valued equally. Due to this analysis, this portion of the video was coded as feminist. This brand messaging aligns with the following feminist values in Figure 3: 5. Confidence; 8. Oppressed as women (this preconceived notion that doing something "like a girl" means doing something frivolously or not seriously implies that females are expected to do things this way); 9. Emphasis on the need for women to be treated "equal but different" to men. (Valued equally in expected actions); 12. Need for change (to change the way this phrase is being perceived/used in American society today); 13. Emphasis on the need for higher self-worth for women (Grant, 1993, p. 140).

In order to further demonstrate the insulting nature of the phrase, Greenfield asked the younger of the two male participants (Always, 2014):

Director: "So do you think you just insulted your sister?"

Participant: "No, I mean yeah, I insulted girls ... but not my sister."

She asked another participant (one of the younger females) a similar question (Always, 2014):

Director: "Is 'Like A Girl' a good thing?"

Participant: "It sounds like a bad thing. It sounds like you're trying to humiliate someone."

These exchanges further highlight the fact that the negative and insulting nature of this phrase is something that is understood and accepted as normal by societal standards. These participant answers also exemplify the oppressive nature of this phrase, and can be coded 
as feminist for their alignment with one of the feminist values from Figure 3: 8. Oppressed as women.

\subsubsection{A girl's confidence plummets during puberty. Always wants to change that.}

One minute and 26 seconds into the video, “A GIRL'S CONFIDENCE PLUMMETS DURING PUBERTY. ALWAYS WANTS TO CHANGE THAT,” appears on-screen before (Always, 2014). For these two on-screen messages, the Always brand name is written in its logo form and in a different color in order to set it aside from the rest of the message. With this messaging, Always is telling viewers that it cares about the lack of confidence in young women/prepubescent women and wants to do something about it. Both of these on-screen messages tie in several feminist values aligning with those in Figure 3: Always, the brand, is communicating an empathetic connection with these "girls" who have lower confidence (5. Confidence) during puberty (Always, 2014). The brand is publicly announcing a need for change (12. Need for change and 13. Emphasis on the need for higher self-worth for women) in the low confidence levels of young women going through puberty. Additionally, Always is suggesting that its commercial campaign can help bring about this change and solve this problem for young women. Furthermore, it can be noted that changing the meaning of "Like a Girl" from negative to positive encourages placing higher value on Women as a category and encourages the change for woman to be seen as "equal but different" to men (Grant, 1993, p. 140).

Continuing from this topic, Greenfield asks the older participants: "So when they're in that vulnerable time, between 10 and $12 \ldots$ how do you think it affects them when somebody uses 'like a girl' as an insult?” (Always, 2014). This question was coded as feminist, as it invokes thought about the feminist values in Figure 3: 9. emphasis on the need for equal treatment between men and women and 13. need for higher self-worth for young, developing women. One of the older female participants responded to this (Always, 2014):

I think it definitely drops their self-confidence and really puts them down, because during that time they're already trying to figure themselves out. And when somebody says, 'You hit like a girl' it's like-well, what does 
that mean? Cause they [young females] think they're a strong person. It's kind of like telling them that they're weak, and they're not as good as them [males].

This answer aligns with several Feminist values from Figure 3: The participant, reflecting on the derogatory nature of the phrase, recognizes this as a negative and oppressive ( 8 . Oppressed as women) phrase. She is concerned for the negative impact this type of phrase has on young women/prepubescent females (5. Confidence - concern for this phrase negatively impacting female confidence). She also expresses a concern for this phrase because it is causing young women to believe they are "weak" or "not as good as" men (9. Emphasis on the need for women to be treated "equal but different" to men — valued equally) (Always, 2014).

Greenfield then asked the older participants to advise "young girls who are told they run like a girl, kick like a girl... hit like a girl...swim like a girl" (Always, 2014). The participant who answers this question is an adult female who has not been depicted thus far in the video. Her response is as follows:

Keep doing it, 'cause it's working. If somebody else says that running like a girl, or kicking like a girl, or shooting like a girl is something that you shouldn't be doing, that's their problem. Because if you're still scoring, and you're still getting to the ball on time, and you're still being first...you're doing it right. It doesn't matter what they say. Yes! I kick like a girl, and I swim like a girl, and I walk like a girl, and I wake up in the morning like a girl because I am a girl. And that's not something that I should be ashamed of, so I'm going to do it anyway. That's what they should do.

This participant's answer is mostly voiced-over with video footage of some of the other female participants (young and old ages) throwing, running, kicking, hitting and doing things with strength and confidence to perform "like a girl." This footage is taken from later in the video, when the participants are asked if they would like to try performing "like a girl" again. This time, everyone is doing it to their fullest ability and not to fit the negative meaning associated with the phrase.

The blend of this inspiring and passionate message, combined with the footage of the other female participants doing things to the best of their ability, makes for an 
emotionally heavy and positive moment in the video. This blend of audio and visuals shows the "change" and the passion that the brand Always wants the audience to see. By showing this participant's personal take on the subject (a positive, relatable, and inspiring message) on behalf of the brand, Always is attempting to form a connection on a personal level with viewers.

This response exudes confidence, strength, self-worth, independence, value on womanhood and acceptance of self, need for change and to be treated as equal in value to men. It is a message communicated with passion and meant to give inspiration connecting with the videos' audience emotionally. Due to this analysis, values listed above from the participant's response were coded feminist because of their alignment with values from Figure 3: 5. Confidence, 11. Choice, 13. Emphasis on the need for higher self-worth for women. These values are apparent with the participant's proud statement that she does things "like a girl" because she is a girl, and "that's not something [she] should be ashamed of' (Always, 2014). This participant's response also aligned with the feminist value of: 6 . Attitude, because the participant is passionate in her delivery and tone. Additionally, this participant's response aligned with the feminist values of: 1 . Independence and 3. Individual freedom, because she says that if "somebody else" is saying that one shouldn't be doing something "like a girl" then that's "their problem" (Always, 2014). She believes that young women should be happy with themselves and their own personal abilities.

At the end of the video, when the older participants are asked if they would like to try performing "like a girl" again, they all perform it to their fullest ability and not to fit the negative meaning associated with the phrase. During this portion of the commercial, there is footage of the smiling older female African-American participant, affirming her wish to "redo" her version of what it means to do something "like a girl" (Always, 2014). This positive connection to the brand's message of changing the meaning of "like a girl" is demonstrated visually here.

The video ends with the on-screen words: "LET'S MAKE \#LIKEAGIRL MEAN AMAZING THINGS. JOIN US TO CHAMPION GIRLS' CONFIDENCE AT

ALWAYS.COM," and then the last on-screen message of: "Rewrite the Rules ALWAYS" (Always, 2014). With the last message, in addition to the brand logo being centered on- 
screen are buttons that appear beneath it which encourage viewers to participate in the campaign:

1. "SHARE to inspire girls everywhere

2. "TWEET the amazing things you do \#LIKEAGIRL"

3. "STAND UP for girl's confidence at ALWAYS.COM"

In this messaging, the hashtag "\#LIKEAGIRL," "ALWAYS.COM" and "Rewrite the Rules ALWAYS" are in a different color from the rest of the messaging (Always, 2014). This is likely done to associate the brand Always, its website, and the products advertised/sold on its website with the social change and the values behind the feminist movement. These on-screen messages emphasize the Always message: the brand is changing an oppressive, negatively perceived phrase into something that encourages higher self-worth, confidence and ability in women.

Due to this analysis, this portion of the video was also coded as feminist. Much of this messaging overlapped with the feminist values from Figure 3: 12. Need for change, 5. Confidence, 8. Oppressed as women and 13. Emphasis on the need for higher self-worth. This is largely because Always is asking viewers to "join" the brand in helping to change the oppressive meaning behind the phrase and build upon "girls' confidence" and selfworth (Always 2014). Always is attempting to inspire viewers enough to "join" in this fight by sharing the hashtag, following the brand's social media, spreading the word about the campaign and, essentially, advertising on behalf of the brand (Always 2014). This shows how this commercial could be seen an example of commodity feminism: the brand is asking viewers to take action in a way that promotes the brand Always through incorporation of the "cultural power and energy of feminism" in its messaging (Gill, 2008, p. 39).

This video encouraged feminist values, but the end result was the advertisement of a brand, the brand's connection with its target audience and the audience's ability to "share" this campaign. This is an example of commodity feminism: the Always brand name giving viewers the impression that Always is bringing about change ... when it is 
actually just advertising for the Always brand. The only possible route for feminist change within this commercial is that, though the commercial's true intent was to sell a product, it did so through gaining the attention of its target audience and raising awareness about a truly iconic and recognizable, oppressive phrase.

Through this in-depth video analysis, only feminist sign values were found within the messaging. None of the camera angles zoned in/fragmented areas of the female participants' bodies in the video. Most of the camera angles used were wide shots (when they were acting out doing things "like a girl") and medium shots of the participants (when they were speaking to the camera). The researcher looked closely for any close-up/detail camera angles in the video during this analysis and for moments of fragmentation, gazes, poses and other feminine visual signifiers, but did not note any within this particular video. This is not to say however, that feminine visual signifiers should be wholly dismissed from this research or future research of this type. The feminist values discussed within the literature review and highlighted within the analysis are listed in the table below along with the level of frequency with which they were coded to occur in the video:

Table 1

Feminist Sign Values from Video Analysis

\begin{tabular}{|l|l|}
\hline Value Found & Frequency of Occurrence \\
\hline Independence & 1 \\
\hline Individual freedom & 2 \\
\hline Confidence & 8 \\
\hline Attitude & 1 \\
\hline Oppressed as women & 9 \\
\hline $\begin{array}{l}\text { Emphasis on the need for women to } \\
\text { be treated "equal but different" to } \\
\text { men. (Valued equally) }\end{array}$ & 9 \\
\hline Choice & 1 \\
\hline Need for change & 3 \\
\hline $\begin{array}{l}\text { Emphasis on the need for higher } \\
\text { self-worth for women }\end{array}$ & 8 \\
\hline
\end{tabular}


According to this analysis, the most frequently occurring feminist sign values/signifiers within the coded video messaging were: the oppression of women, emphasis on equality between the value/expectations of men and women, emphasis on the need for higher self-worth for women and confidence. Others noted within the video analysis were: independence, individual freedom, attitude, choice and a need for change. As these feminist values were all noted within the video analysis, it is evident that they were the most prominent of the feminist values present in the messaging of this example of commodity feminism.

The above summary analysis followed the fourth step of the constant comparative technique: "simplifying and integrating data into a coherent theoretical structure" (Wimmer and Dominick, 2014, p. 121). In this step, the researcher summarized the findings of the research and the results of the analysis - "integrated into some coherent explanation of the phenomenon" (Wimmer and Dominick, 2014, p. 121). The aim of this step was to better understand the data within the study. This was done just after the initial analysis: the findings of the analysis were summarized, and their meaning in relation to the research questions and the framework of the study were examined. This analysis set up for the second stage of the research process: focus group research.

As was the intention of this video analysis, the information found from the analysis helped to provide answers to the first two research questions of this study. In response to RQ1: Yes, this video does communicate nine of the 18 feminist values of commodity feminism as defined by Goldman. These responses have been extricated, highlighted and analyzed within the video analysis. Developed from this information, upon further analysis of the feminist sign values/feminine visual signifiers found within the video analysis, is a response to RQ2. In response to RQ2: As nine feminist sign values were identified and extricated from this video analysis, it can be stated that all are associated with feminism and the feminist values discussed in the literature review.

\subsection{Focus Group Findings}

Answering these first two research questions via the information interpreted from the video analysis was an important step toward executing the next stage of research: focus groups. The findings from the data analysis supplied the information needed to prepare the 
questions for the moderator's guide. In addition to this, after examining the major findings from data analysis, the researcher was able to tighten the scope of investigation for RQ3 and RQ4 for the next method - focusing primarily on the feminist sign values. It is, again, important to note that the possibility of information arising in association with the feminine signifiers identified by Goldman in the literature review were not dismissed entirely from the scope of investigation. However, the identification of a large number of feminist sign values discovered in data analysis did focus the rest of the research largely on the investigation of these values in regard to the next method of investigation.

The purpose of conducting these focus groups was to collect data and later yield potentially rich information to answer RQ3 and RQ4. The analysis of these focus groups included that of the pretest focus group (referred to as focus group 3 or "FG3") in the following discussion. The data collected in the pretest was included in the analysis because it was conducted using the same sample type, size, questions and setting as focus group 1 and focus group 2.

Although previously stated, the research questions should be reviewed again (this time more focused after the video analysis) before delving into the discussion of the major findings of focus group analysis: RQ3 attempted to identify which feminist sign values within the video communicated positively with the audience. In addition to this, RQ4 attempted to identify which feminist sign values within the video connected most effectively with the audience. The following discussion highlights the major findings from the analysis of the data collected from the focus groups, excerpts from the coded transcripts to support these findings, and answers to the RQ3 and RQ4.

\subsubsection{Participant Experience with the Brand Always}

In order to fully evaluate whether the commercial effectively or positively connected with the focus group participants (as RQ3 and RQ4 investigate), it was important to first understand each participant's experience with the brand Always prior to the focus group discussion. In addition, it was important to know whether the participants had seen the commercial before the focus group, in order to ascertain their initial reactions to the video. For this reason, all focus groups were asked about their experience with the brand before the focus group discussions, whether they had seen the video prior, where 
they had seen it (if they had), and their initial reactions to the video when they had first watched it.

It was subsequently discovered that all but one of the 30 participants of the focus groups (a male participant) were at least aware of and familiar with the brand Always prior to viewing the commercial and joining in the focus group discussion. All participants who were aware of the brand reported having either a positive or neutral perception of the brand before viewing the commercial video. Those participants (all female) who had used the brand's products before, or were current users of the brands products reported having a positive experience with the brand. Most focus group members (26/30 total members) had seen the commercial video at least once before viewing it within the focus groups. Those who had already seen the commercial reported seeing the commercial for the first time on YouTube (either as an advertisement prelude to a video they searched to watch or via a direct search for the video), on Facebook shared by family and/or friends, on Twitter shared by family and/or friends or during the initial airing of the commercial during the 2015 Super Bowl.

\subsubsection{Investigation of $R Q 3$}

In order to answer RQ3, all relevant coded materials were examined and interpreted for their meaning in relation to the research question. One of the most relevant coded subcategories to RQ3 from analysis included that of "Positive Connection" concerning participant's connection to the video and its messaging. Many of the participants reported that they liked the video message and felt positively toward the commercial when watching it; recurring positive emotions which participants reported they felt while watching the video included feelings of empowerment, inspiration and relatability. An example of this is seen in the quote below from a female participant of Focus Group 2 (FG2):

(FG2) Mary: I liked it because I related to some of the older girlsespecially when they said how-like when you grow older you really have a drop in your self-confidence. And I remember, like when I was younger, I was so much more confident in myself - that I could do things. But through that part I felt it was really, really relatable to me. 
Two parts of the video were found to have stood out to and connected more positively with the participants of all focus groups. This was discovered during the analysis of each focus group transcript via recurring coding of "Positive Connection" and "Feminist Sign Value" associated with participant's memory and connection to these parts of the video. The part of the video that connected most positively with participants was the speech made by the older female participant in the video in the blue dress. This speech, which was included in the data analysis of the video, spoke to the need for self-acceptance and confidence and to the ability of women to be equal in the value of performance to men. In connecting positively to this speech, participants connected positively to the feminist values of: confidence, choice, emphasis on the need for higher self-worth for women, independence and individual freedom. These feminist values were those identified during the data analysis of the video.

Most female participants reported feeling empowered by this speech and said that the sincerity, inspiration and self-acceptance of the message is what they connected with most positively. In addition to this, female participants reported feeling positively about being able to relate to what she was saying and connecting with them on a deeper level. Many also quoted parts of this speech directly when reporting a positive connection to the video. Examples of this positive connection to this part of the video messaging can be seen in the following quotes:

(FG1) Caitlin: I think that the one part that honed in every little thing that all the kids and the adults were all saying was the girl in the blue dress who had the little speech. And, I think that's what honed it in because she was able to use or sound conversational but like even if you were a little kid or an adult like you could listen to her and hear what she's saying and be able to relate to it and understand where she's coming from. So I think that's really what was able to able to bring the whole commercial together. That was a good ending, you know, last bit of words 'cause everyone else, you know, you saw them acting and she was the one who kind of like...gave the overall vision of the commercial.

(FG2) Marie: I liked when the one girl was accepting that she does things "like a girl." She listed off that she runs like a girl because she is girl and she wakes up in the morning like a girl because she is a girl. So that's the 
same as how I was saying earlier - that she's taking the message and making it a positive thing.

Considering the feminist values that were identified in this speech above, and the overall positive connection that participants report feeling to this video, these feminist sign values were identified as having communicated very positively across all focus groups. Participants reported that they were able to relate and connect to the message within this speech because they felt that the woman in the blue dress was sincere. Many female participants reported feeling empowered and inspired by this speech. Others also noted that the music (which increased in volume and pace) as well as the video footage of the participants in the video performing "like a girl" again and doing so to the best of their ability were parts of what made this portion of the video so empowering.

Along with the above portion of the video, many participants reported feeling positively and strongly toward the change Always and the commercial messaging were trying to make. This is in reference to the portion of the video where the older participants are asked if they would like a chance to perform "like a girl" again, and then perform it with strength and seriousness - like the younger participants performed it in the video. Some focus group participants felt a particularly positive connection to this part. This change ties into the speech mentioned above, in that the woman in the video is accepting the way she does things as "like a girl" to mean that she does things like herself. Focus group participants liked that Always' commercial messaging was not attempting to erase the derogatory phrase completely, but to change the meaning into something that is positive, empowering and constructive for women. Many reported that this was the most important part of the video messaging to them personally because they see it as a change that needs to be made. Examples of this positive connection to this part of the video messaging can be seen in the following quotes:

(FG1) Lizzie: The part that really got to me was when they asked: "Do you want to demonstrate again what it means to run 'like a girl.' And then all of the women immediately said: "Yeah I do" and then they did it normally. And, I feel like it shows growth through just a really simple statement and ... how quickly you can see the error in the phrase "like a girl" if you just 
call attention to like — Hey why does it matter If you say "like a girl?" So, I just think - it's a very easy change. I feel like the commercial showed how easy of a change it is to make in just a few people... and how easy it could be to change like, the culture of the statement "like a girl." ... I felt really positively about it because - it's a change that I think needs to be made, and I don't think people realize that it's a change that needs to be made until like — it's brought up in a commercial like this.

Focus groups reported having a positive connection to this "change that needs to be made" in order to make the phrase mean something more positive, boost self-confidence, selfworth and show that women should be valued equally to men. These positive connections were coded in analysis as "Feminist Sign Values," as they are directly related to several feminist sign values. These corresponding values are: confidence, need for change (from an oppressive phrase), emphasis on the need for higher self-worth for women and emphasis on the need for women to be valued equally to men (in regard to their ability).

As these portions of the video were frequently reported as being the most well "liked," "relatable," "empowering," "significant" and "inspiring" and connecting in an overall positive way to participants across all focus groups, it was surmised that these were the most positively communicative parts of the video. Once this was found, these parts of the video were closely examined and found to include the previously mentioned feminist sign values of: confidence, need for change (from an oppressive phrase), emphasis on the need for higher self-worth for women, choice, independence, individual freedom and emphasis on the need for women to be valued equally to men (in regard to their ability). Therefore, in response to RQ3: it was found that the above feminist sign values communicated most positively with the audience.

\subsubsection{Investigation of RQ4}

In order to answer RQ4, all relevant coded materials were examined and interpreted for their meaning in relation to the research question. One of the most relevant coded subcategories to RQ4 from analysis included that of "Effective" concerning participant's connection and response to the video and its messaging. However, other subcategories that were sorted under the parent category of RQ4 and tied into effective included materials coded as having "Positive Connection," "Negative Connection" and "Feminist Sign Value" 
with regard to reported participant connection to the video and its messaging. It was noted, during analysis, that there was a significant amount of overlap in the positive and effective connections reported from focus groups. Considering the amount of overlap between the categories of RQ3 and RQ4, it can be surmised that much of what connected to participants on a positive level also connected with them effectively.

Many focus group participants reported feeling positively about the fact that this commercial was very different from and more memorable than commercials from other companies. This was reported by both male and female participants across focus groups. Several participants stated that they would remember this brand and this commercial because of the positive messaging content in the video, in that it stands out to them in comparison to others. Female participants across all groups reported having a stronger brand awareness and a more positive association with the brand after seeing the video, in that they believe that the brand cares about women and the empowerment of women.

More specifically, female participants in focus group one reported having a more positive perception of the brand after watching this commercial because it stood out from other feminine hygiene product commercials concerning the messaging within the commercial. Always now stands out to focus group one participants in comparison to other brands, because this commercial speaks out about an important issue regarding women and resonates with its audience. They also liked that Always was marketing this with more prominence in the commercial than its actual brand name and products like other brands. This commercial made them feel that Always cares about them as the consumer.

Overall, the memorability of this video in the eyes of focus group participants across all groups is indicative of an increased brand awareness and enhanced overall perception and relation to the brand as compared to other brands and other feminine hygiene product brands. Examples of this are seen in the supporting quotes below:

(FG1) Linda: I think it made me feel positive about that brand because their whole advertisement was more about bringing to light an issue that surrounds women and girls and with the whole "like a girl" thing. And it was more about bringing that to light instead of just showing that product — which a lot of other feminine advertisements do. They ... you know ... you see women, and you see the product and they're saying you know "oh 
this will make your life better," or "it will make it easier for you," or "make it nicer." Where this ad was more about revealing an important situation that needed to be talked about ... and that more important to Always than showing the product. Like (talking from Always' perspective): "We feel like it's important to ... bring to light this situation about women because we care about women, but we also have feminine products. So, we care about all the aspects of women.

(FG2) Andrew: I gained a positive image of the brand from this commercial because they weren't trying to sell you any products, they weren't speaking to the utility of the product at all. So I think that was a very - they really cared about the message vs. attaching the positive message to their product. I think I've seen other commercials used different "meaningful" things — like Budlight — with the horse and the kid — like meaningful message, whatever - to make you associate their brand with a positive message. But you don't see the word "Always" until like the very end. And I didn't even know what the brand was before then — the first time I saw it.

(FG3) Nina: It definitely made me feel more positive about the brand. And, if I were to go into a store and they sell that [brand] I would remember the campaign vs. like another company where I don't really know anything about them or they don't have any advertisements I know about. I would think positively about Always.

These excerpts exemplify how the video content effectively connected in a positive way to the male and female participants across all focus groups. More specifically, their positive connection to this commercial was largely due to the fact that its messaging was important to them, stood out from other commercials and was considered by all to be more memorable in that way. As mentioned in the operational definition of effectiveness, an increased brand awareness, enhanced positive perception/outlook of a brand and an increased likelihood to buy the product based on a connection (all represented in the quotes above) are factors of effective brand communication (Joseph, 2010).

Analyzed further, these effective connections to the commercial were also coded as "Feminist Sign Values." It was found that the previously discussed female participants who found this commercial to be more memorable than other feminine hygiene brands mentioned that this was due to the "issue" (in regard to the derogatory use of the statement) that was brought to attention with more emphasis than the product or brand name. 
Additionally, female participants reported that they connected positively and found the commercial memorable because it empowers women, promotes confidence, selfacceptance pride in being a woman and emphasizes a need for change in the way that the phrase is used. The feminist sign values which correspond were: confidence, need for change, need for higher self-worth in women and a need for women to be valued equally to men. This finding is significant in that it not only yields a partial answer to RQ4 by supplying feminist sign values in the video which connected effectively to the consumer, but it reinforces the answer to RQ3. This finding supports the notion that the same identified sign values mentioned earlier in answering RQ3 (which communicated most positively) also connected effectively with the audience.

Speaking to actions made on behalf of the effective connection the commercial video had with focus group participants, it was reported across all focus groups that many of the female participants shared this commercial on various types of social media platforms after seeing it initially. These social media platforms include Facebook, Twitter and even Weibo - a Chinese social media platform. In addition, several participations used this commercial for class presentations, and one reported having a class discussion about the commercial in her Women's and Gender Study course. Along with this, many female participants reported seeing their female friends and family sharing the commercials on the same platforms, and sending the commercial via direct message. The participants who shared on their personal social media said that they did so because they were able to relate to the messaging and felt inspired, empowered and confident after watching it. Focus group participants reported that their female family members/friends shared the video alongside personal messages saying that they themselves also found the video messaging to be positive, relatable and empowering.

The relatability of female participants and female friends/family of participants to this message corresponds with the way in which the phrase "like a girl" is used in society today - with an oppressive and negative connotation. This relates back to the parts of the analysis where it was found that much of what was categorized as relevant to RQ4 and coded as "Effective," was also coded as having a "Negative Connection" to focus group participants. Female participants across focus groups reported that when watching the 
video, they were able to relate personal memories and experiences back to the derogatory use of the phrase "like a girl." They recognized and remembered this feeling of oppression that comes from the phrase as it was used when they were children - by siblings, teachers, friends, etc. These female participants related to it because of the shared experiences they have had concerning the oppressive nature of the phrase. They, too, can identify with being oppressed as women, and many shared it because they realized that others would understand the same experience.

In fact, most negative reactions to the video were largely in connection to the female participants relating to the negative nature of the phrase and how it made them feel - angry, annoyed, frustrated - when it was used in a derogatory fashion. Many female participants related to the oppressive meaning behind the phrase based on past experiences, and felt negatively toward the part of the video when the older participants performed the stereotype instead of performing to the best of their ability. This indicates that these female participants identify with shared and relatable experiences as women being oppressed as women - making them think about the phrase and how it was used based on their own experiences. Following from this, the initial negative shared experience also brought some female participants to have more positive feelings and connectedness to the video when the younger participants were asked to perform "like a girl" and did so to the best of their ability. This change in attitude based on the change in messaging relates back to focus group participants identifying with the need for change communicated throughout video messaging. Examples of these findings are supported by excerpts of focus group transcripts below:

(FG1) Linda: I would say, the initial part where - when women were asked to do something "like a girl" they immediately fell in with the stereotype of girls not doing something well, or, girls looking silly when they do things. That was just sort of like a negative point, but at least the ad later redeemed itself by you know ... once they were talked to about like: "can you see why this is a negative stereotype?" You know they ... they changed the way they did things.

(FG1) Lizzie: ...It like reminded me of a lot of past experiences I've had because I used to play a lot of sports when I was little — like really little - 
like the ages of like the children that they showed [in the video]. And my older brother and his friends would always say like: "you're throwing that ball like a girl" or "running like a girl" or "you're doing all this stuff like a girl" - and they made it sounds like I was doing it wrong and ... I mean I probably was - I didn't know how to play sports - but the idea that like, someone who didn't know the proper way to do something was doing it like a girl ...? I didn't know how to play sports ... so therefore I was playing sports "like a girl?" It just reminded me of that and how stupid that phrase was ... if I can say that - because...I was just reminded of how much disdain I held for that phrase. And ... I had kind of forgotten that and, honestly, I probably would have portrayed "like a girl" the same way those women did in the beginning without even thinking of my past experiences with the phrase. And that just shows how much change needs to be had in the context of the phrase "like a girl." And I think it really did like ... change my view on that phrase.

These were all coded as "Negative Connections" to the oppressive nature of the phrase, how the stereotype was perpetuated in the video and how the participants shared their oppressive experiences related to the phrase. These "Negative Connections" were coded as "Feminist Sign Values" as well. In addition, the negative connections of female participants that were reported to have been changed to positive connections were regarding the change of meaning of the phrase (from negative to positive) in the commercial messaging. Both of these portions of analysis were coded as "Feminist Sign Values." This is because the specific negative connections reported by female participants correspond to the feminist sign values of being oppressed as women, while the positive change corresponds to the feminist sign values of: emphasis on the need for change, emphasis on the need for women to be valued equally to men and emphasis on the need for higher self-worth in women. These female participants, across all groups, connected to and related personally to the shared negative experiences of this phrase having a negative impact in their lives. In addition, the same female participants connected to and related personally to the positive change that the commercial messaging was trying to make. This change is something participants identified positively with, as they saw it as a change that needs to be made to empower women and keep them from sharing the negative experiences they were reminded of in the video. 
Following from these reactions to the above portions of the video, it is important to note the messaging at the end of the video: "Let's make \#LikeAGirl mean amazing things. Join us to champion girls' confidence at Always.com." This message speaks to the previously discussed emotions of focus group participants, saying that Always also sees a need for change in the oppressive meaning of the phrase "like a girl," and wants it to have a more positive meaning and to "champion girls' confidence." The commercial messaging then asks viewers to share the message "to inspire girls everywhere," to tweet the "amazing things you do \#LikeAGirl," and to "stand up for girl's confidence at Always.com." This messaging offers itself as a solution to the negative connection focus group participants reported relating to in the video - this is what ties into the positive feeling focus groups participants expressed. The feminist sign values of a need for change in the oppressive nature of the phrase, (and to do so in order to increase confidence in women) emphasizes the need for higher self-worth in women are all expressed in this portion of the video that connects on an emotional level with participants. Always' encouragement to share and tweet this message is tied in with the idea that doing so will result in the change that is needed concerning the oppressive meaning of the phrase and an increase in confidence and self-worth in women who see it.

These feminist sign values in the messaging at the end of the video are what connected with viewers, on top of the overall message, subsequently making them feel that the solution to the negative experiences they remember is to spread this message to others in order to spread the same negative to positive connection. That said, the feminist values of a need for change, confidence in women, need for higher self-worth in women and shared experiences of oppression as women are what drove these focus group members to feel inspired, empowered and differently about how they thought about the phrase. In addition, these same feminist values drove these focus group members to take action and share the commercial - as well as the reported family and friends who shared with the focus group participants because of the inspiration and empowerment that they felt from the message. Although the female participants were those who reported being able to relate, and having shared/acted as a result of their connection to the video, male focus group participants also reported thinking more and feeling differently about the oppressive phrase 
after having watched the commercial. These feelings of negative emotional connection, relatability, inspiration, empowerment, thinking differently about the brand/phrase and getting the drive to take action and share the message all tie into what was previously defined as "effective" connection to the consumer. And, based on how the focus group members reported seeing "everyone" share it on their social media when the commercial was initially aired, it is seemingly something that connected effectively to the consumer at a general level concerning these feminist values and the feelings of inspiration and empowerment that are driven from them.

This finding indicates that a negative connection in a homogenous focus group (concerning shared negative/oppressed experiences as women) can in turn bring about a positive and/or effective connection. Following from this, and to address RQ4, it can be understood that the feminist sign values which connected most effectively with the audience include those which connected most positively and, even more so, those which connected most negatively in a relatable fashion. Therefore, in response to RQ4: the feminist sign values which connected most effectively to the audience from the video include: a need for change, confidence in women, need for higher self-worth in women, and shared experiences of oppression as women, choice, independence, individual freedom and emphasis on the need for women to be valued equally to men (in regard to their ability).

It is important to note, based upon these findings, that what is a positive or negative connection may also be an effective connection with regard to the consumer concerning the use of commodity feminism in advertising messaging. Those phrases which were commonly reported by participants to have been inspiring and empowering were tied into parts of commodity feminism as defined by Goldman. These communicated parts of commodity feminism connected most effectively with female participants (considering the strongest actions being taken - sharing and liking the commercial) when the communication first connected with participants in a negative and retable manner, but later offered a solution. This connected to female participants in a negative but relatable way and showed participants how the phrase is oppressive based on their own personal experiences. It is also important to add that, though this may be because of the products sold by Always 
(feminine hygiene products), the fact that the majority of the focus group participants were female and/or the messaging content, the most effective connections noted from analysis were made with female participants. That said, female participants' feelings of oppression were amplified by showing that others (those in the commercial and those sharing/liking the commercial on social media) had also lived shared negative experiences involving the phrase. This combination of personal and shared negative experience, followed by a positive change that inspires and empowers (through factors of commodity feminism) are what drove an effective connection to the audience. In addition to this effective aspect of the commercial, the fact that the commercial used real people and that it was directed and produced by a female director connected with focus group members due to their belief in the sincerity of the message. This message was presented in a different format from other commercials, and spoke about an issue important to its audience. These factors of the messaging, as well as the execution of the messaging itself and the factors of commodity feminism which connect on the deepest level of the consumer, tied in together the effectiveness of the commercial overall.

\subsection{Skepticism from Focus Group Participants}

It is lastly important to note in this chapter that there was a recurring theme among focus groups concerning the belief that Always' objective in the production of this commercial and the overall campaign was to make money, and not to change the perception of the phrase "like a girl." Generally, focus group participants believed that the main goal of this commercial campaign was to connect positively with its audience through female empowerment messaging in the video in order to change the buying habits of viewers in favor of the brand. Many believe that the messaging has a possibility of positive side effects, but, overall, they think that the underlying purpose of the campaign is to increase product sales. Examples of this opinion can be found in the excerpts of the focus group transcripts below:

(FG1) Celia: I think the purpose of the commercial is so that the viewers the next time they're in Target or Walmart and they have the choice between Tampax or Playtex or Always and they're purchasing their feminine products, they're going to have that — even if it's subconscious 
— that positive connection with the brand Always or even the logo, from watching that commercial. And the feeling they had when the commercial finished, and they'll choose Always over the other brands that they may or may not have that positive connection to.

(FG2) Selma: I believe they do believe in their own message - like they do want to change "like a girl," but I think the underlying reason they made this commercial is because they knew that this would change a lot of people's opinions towards the brand and then that might influence secondhand effect buying habits even though they weren't directly advertising their products. I think they knew that spreading this empowering message was gonna change - that's geared towards women - is gonna change the women's buying habits. Even though they're not directly mentioning them. So they believed in their message but the whole reason that they made this message was to get more people so buy their stuff.

Focus group participants did agree that Always was still a believer in the message, that the brand cares about the consumer (as is seen in the messaging) and that the spreading of this message had benefits in that it empowers the consumer. However, participants across all groups (male and female) believe that the main purpose of this commercial was to generate sales based on the positive and inspiring connection made with the audience through the commercial. This shows that, though the commercial identified as an example of commodity feminism by the consumer and within this research, it is still effective in its connection to the audience. Focus group participants acknowledge the commodity feminist aspect as the underlying reason for the message, but are still positive about the video overall. 


\section{CONCLUSION}

The purpose of this chapter is to summarize the purpose of the study, reiterate the major findings of the study and tie these into the introduction. Additionally, this chapter discusses the implications, limitations and future areas of suggested research which could emerge from this study. These topics of discussion will be covered within the following paragraphs, in order to conclude and resolve the introduced questions and ideas from the beginning of this research.

\subsection{Overview of the study}

This study explored the connection between the Always \#LikeAGirl commercial and its viewers. Through this exploration, the study aimed to find and highlight any feminist sign values and/or feminine visual signifiers identified in the Goldman et al. (1991) definition of commodity feminism. The research questions developed from this purpose were:

RQ1: Does this video communicate any of the feminist values/feminine visual signifiers of commodity feminism as defined by Goldman?

RQ2: Are the majority of these feminist values/feminine visual signifiers associated with femininity or with feminism?

RQ3: Which feminist values/feminine visual signifiers of commodity feminism within this video communicated positively with the audience?

RQ4: Which feminist values/feminine visual signifiers of commodity feminism connected most effectively with the audience?

In order to explore these research questions and find answers to each, two types of qualitative measurement were utilized. These two methods of measurement were a content analysis of the commercial video followed by focus groups. A data analysis was completed to code the commercial in detail as either "feminine" or "feminist" in accordance with the feminist sign values/feminine visual signifiers identified by Goldman et al. (1991). This was to categorize the information in the video and find answers to RQ1 and RQ2 and to prepare for the second method of measurement that would answer the final two research 
questions. During this method of measurement, following the Wimmer and Dominick (2014) data analysis guide, only feminist sign values were coded throughout the video messaging. A total of nine feminist sign values were identified throughout the data analysis. The feminist sign values occurring most frequently were: the oppression of women (oppressed as women, coded nine times), emphasis on equality between the value/expectations of men and women (coded nine times), emphasis on the need for higher self-worth for women (coded eight times) and confidence (coded 8 times). Others noted within the video analysis were: independence, individual freedom, attitude, choice and a need for change.

As was the intention of this video analysis, the information found from the analysis answered the first two research questions of this study. In response to RQ1: Yes, this video does communicate many of the feminist values of commodity feminism as defined by Goldman et al. (1991). In response to RQ2: As only feminist values were extricated from this video analysis, it can be stated that all are associated with feminism and the feminist values discussed in the literature review.

Following from the first method of measurement, the questions for the moderator's guide were prepared based on the results of the data analysis. This was done after the first method of analysis in order to better hone in on the exploration of the second two research questions regarding the feminist sign values in the video's connection to the audience. These feminist sign values identified in the data analysis were then utilized within focus group discussion to determine whether respondents identify them within the commercial content. And, if respondents identified with them, whether they create a positive or negative emotional connection and/or an effective connection.

As was the intention of the focus group research, the information found from the analysis helped to provide answers to the second two research questions of this study. In response to RQ3: It was found that the feminist sign values which communicated most positively with the audience were: confidence, need for change (from an oppressive phrase), emphasis on the need for higher self-worth for women, choice, independence, individual freedom and emphasis on the need for women to be valued equally to men (in regard to their ability). And, in response to RQ4: The feminist sign values which connected 
most effectively to the audience from the video were: a need for change, confidence in women, need for higher self-worth in women, and shared experiences of oppression as women, choice, independence, individual freedom and emphasis on the need for women to be valued equally to men (in regard to their ability). In addition to these findings, in the focus group analysis it was found that there was a large amount of overlap in what connected positively to focus group participants and what connected effectively. Some of those feminist sign values which communicated most positively with focus group participants also ended up connecting effectively with focus group participants. The most effective connection to the consumer from this video, however, was found to be the negative connection followed by a positive connection (with regard to a change/solution being made to remedy the prior negative connection with the participants). This combination of emotional connection was associated with the most effective participant responses to the video - that which included feeling more positively about the brand, liking/sharing the video on social media platforms and making the brand stand out more than others because of its messaging in the video.

Lastly it was found that, although many focus group participants felt positively about the brand Always, they still thought that the underlying purpose of the video was to generate sales based on the positive connection made with the consumer. This is important to note, as it ties into similar results of the Dove Real Beauty summary mentioned in the Introduction and Chapter 1 of this study. In the findings of the Dove Real Beauty study (slightly similar study design concerning methodology) the researchers tried to find whether the commercial messaging was considered feminist through a focus group discussion with feminist participants. These participants end up believing that the commercial is not feminist, but was done in order to increase sales based on feminist concepts (Taylor et al., 2016).

In the beginning of this study, the researcher questioned whether this was an example of commodity feminism as defined by Goldman et al. (1991) or if it was a route for feminist change. Based upon the findings of this study, it can now be assumed that, yes, this commercial (like the Dove Real Beauty Campaign) is indeed a well-executed example of commodity feminism. This is because it effectively communicates aspects of commodity 
feminism in a way that connects positively with the consumer and makes the audience feel better about the brand image. However, unlike in the Dove Real Beauty Study, the participants of this study see this as a way to generate sales in addition to seeing it as a positive message with positive possible side effects. Focus group participants still aligned themselves with the Always brand and the change that the brand is making to the negative meaning associated with the phrase, despite the fact that they see that the brand has an ulterior motive of communicating this message in order to generate sales. That said, it can be surmised that though this commercial is a well-executed example of commodity feminism, it may also have positive side effects with regard to feminist change.

\subsection{Implications}

Theoretically, the previously summarized findings of this study may contribute to the marketing communications field by yielding informative observations concerning persuasive communication tactics to connect with the personal values of the audience. These persuasive tactics include creating advertising messaging using the most effective aspects of commodity feminism (those identified in this study) in a way that first connects negatively with the consumer, and then positively connects through a suggested solution based on the positively connecting aspects of commodity feminism (identified in this study). Although it is suggested that more in-depth research be done to investigate this process at a larger scale, it is possible that this strategy of communication will be beneficial to the marketing communication field. This is because, based upon the findings of this study, messaging structured similar to the messaging from the \#LikeAGirl commercial video connected with its audience in a positive way which made the focus group participants feel more positively about the brand, remember the brand and commercial and like/share the commercial on social media.

The findings of this study extended upon pre-existing research and literature on the topic of female consumerism by providing updated information concerning effective and usable feminist sign values within advertising to the target consumer in regard to products used by female consumers. This study's exploration of the relationship between the audience of this commercial and the messaging in the video exemplified the strengths of the messaging tactics used to connect with this and future audiences. Identification and 
isolation of the feminist sign values of commodity feminism which yielded the most positive and effective connections with this audience will help advertisers to better focus messaging. Advertisers will be able to use this information to produce similar advertisements with a stronger and more effective connection to this audience.

To continue from this, this study contributes not only to the marketing communications field but to the pool of knowledge concerning commodity feminism as it is used in today's world. There are few studies completed within the last five years on the topic of commodity feminism written from the marketing communications perspective as it applies to advertising today (Hains, 2014). This study is one which contributes to and expands upon the existing limited pool of knowledge with regard to the research of commodity feminism in academia and in the marketing communications field.

\subsection{Limitations}

Limitations within this study include the introduction of bias by focus group participants with prior knowledge about the topic of commodity feminism or feminism in general. However, this bias was expected and adjusted for due to the findings in the Dove "Real Beauty" campaign study by Taylor et al. in which the participants did not believe the videos to be considered "feminist" due to the capitalistic nature of product advertising (2016). This possibility of bias was expected and was the rationale behind the strategy to explore the type of emotional connection and level of effective connection between participants and the video instead of whether the content of the video is actually feminist (as the Dove Real Beauty video explored).

Another limitation is the possibility of the moderator introducing bias during the focus group setting/information analysis. To combat the likelihood of these limitations, a well-structured moderator guide was constructed to aid in guiding the focus group conversation and lead the discussion in a way that each individual opinion/thought vocalized and recorded in this particular scenario. In addition, a pretest was conducted in order to help the researcher prepare and adjust for any issues that could have arisen during focus groups (Morgan, 1996). 
Performing the data analysis in the preliminary stages of research could also be seen as a limitation concerning the validity of the information gathered. In order to adjust for this, measures were taken to ensure the validity of the information extracted from the data analysis. For example, the completeness of the data was assured with the rationalization and explanation of each value/signifier found in the analysis. In addition, the categories not found within the analysis were rationalized with a description as to why they were not found within the analysis so that data was not merely being dismissed for not fitting into the research (Wimmer \& Dominick, 2014).

Another limitation to this study was that it involved only qualitative methods of measurement. Qualitative measurement, unlike quantitative measurement, uses smaller sample sizes that are not always representative of the entire population; the results of a qualitative study cannot usually be generalized to the population (Wimmer \& Dominick, 2014). However, for this type of study, qualitative measurement is more appropriate in answering the discussed research questions. This is largely due to the fact that this research follows elements of the interpretative paradigm, a model of qualitative research. This is a type of research which aims to "understand how people in everyday natural settings create meaning and interpret the events of their world" (Wimmer \& Dominick, 2014, p. 115). The interpretative paradigm is a perfect match to the type of research within this study, which aims to investigate the connection, interpretation and perception of a commercial message and its audience.

In addition to this, there are generally apprehensions concerning the use of focus groups as a research method. This is in reference to the small sample sizes associated with focus group research along with the use of convenience sampling. As a result, these sample types are not wholly representative of the population - a limitation found in most types of qualitative research design (Fern, 2001). These issues were adjusted for in this study by recruiting participants "representative of the relevant population of respondents" and the use of a limited number of questions and possible responses in each focus group (Fern, 2001, p. 125). These adjustments minimize risk of the above limitations in focus group research, though it should be noted that future research suggestions include quantitative methods of measurement in order to generalize the results to the population. 
Additionally, focus groups are often criticized for the fact that participant "responses are not independent"; some participants' responses may influence others (Fern, 2001, p. 121). This type of influence can be avoided with a strong and controlling moderator along with the use of standardized procedure and moderator's guide - as was utilized in this study (Morgan, 1996). Lastly, focus groups are often criticized because their analysis and "conclusions depend on the analyst's interpretation ... the investigator can easily influence the results" (Fern, 2001, p. 121). This last criticism, however, is applicable to several popular methods of quantitative research as well (Fern, 2001).

\subsection{Future Research Recommendations}

For future research, it is suggested that a larger number of focus groups be conducted containing an even ratio of male and female participants and focus more closely on the feminist sign values of commodity feminism defined by Goldman et al. (1991). In this way, the consciousness-raising (of feminist values) which occurred in this study among male participants can be further examined at a larger scale. In addition, it is suggested that future research encompass an entire campaign of videos from a feminine hygiene brand (like Always) so that the researcher can identify more tactics and compare their effectiveness. It is also suggested that future research involves focus group participants of a similar age range and socioeconomic status, in order to increase the likelihood of homogeneity within the groups. As mentioned earlier, the homogeneity of a focus group (with regard to shared experiences) often allows the focus group members to feel more comfortable speaking their minds, and to have lengthier discussions rich in data sooner than focus groups with less similar participants (Liamputtong, 2011). This research suggestion may aid in further isolation of the most effective positive and/or negative connections between female consumerism commercial messaging and a female audience. It may also result in an increase in the consciousness-raising of feminist values as a partial route for feminist change. Information of this variety will be greatly helpful in the field of advertising, as it will help advertisers to personalize messaging even more to connect to a specific consumer audience.

Other suggestions for future research include applying a different or more expanded definition of effective connection to the consumer (i.e. focusing more on purchasing 
behavior than on social media interaction) than was used in this study to a similarly structured study. Another suggestion is applying a more focused definition of effective connection to the consumer. This definition could identify an effective connection as one which results in a focus group participant posting about/commenting on/sharing the video on a social media platform themselves, as opposed to the inclusion of thinking/feeling differently about the commercial and/or brand. This would be to better hone in on which tactics/aspects of commodity feminism connect effectively enough to yield direct actions (posting/commenting/sharing on social media platforms) from consumers for the marketing communications field.

A final suggestion for future research is to conduct a similar study of static ads (such as the makeup ad examined in the literature review) associated with a well-known make-up brand. For this research, it may be possible that there are more feminine visual signifiers identified in data analysis than there are feminist sign values. This would yield information on how feminine visual signifiers communicate with the consumer (positively or negatively) and which of them connect most effectively with the consumer. For this study, it is suggested that a content analysis (a quantitative method of measurement) be used so that a large number of messages may be accurately and precisely analyzed and the results will be generalizable to the population (Wimmer \& Dominick, 2014). This suggested research is largely due to the fact that this particular study produced no information about the feminine visual signifier aspect of commodity feminism. In order to fully understand commodity feminism and how it can be used effectively, both sides of the spectrum - feminist sign values (explored within this study) and feminine visual signifiers — must be examined in today's advertisements. 


\section{BIBLIOGRAPHY}

Always. (2014, June 26). Always \#LikeAGirl. Retrieved February 18, 2017, from https://www.youtube.com/watch?v=XjJQBjWYDTs

Always. (2017). Always Feminine Products and Menstrual Information. Retrieved February 19, 2017, from http://always.com/en-us

Belch, G. E., \& Belch, M. A. (2014). Advertising and promotion:An integrated marketing communications perspective (10th ed.). New York, NY: Irwin Mcgraw-Hill.

Bordo, S. (2013). Unbearable weight feminism, Western culture, and the body. Berkeley, Calif.: Univ. of California Press.

Brownmiller, S. (1984). Femininity. New York: Linden Pr. u.a.

Brownell, K. D., Napolitano, M. A., Mongrain, M., \& Van der Feen, J. (1995). Distorting Reality for Children: Body Size Proportions of Barbie and Ken Dolls. International Journal Of Eating Disorders, 18(3), 295-298.

Carson, D., Gilmore, A., Perry, C. \& Gronhaug, K. (2001). Qualitative marketing research London, : SAGE Publications Ltd doi: 10.4135/9781849209625

Craft, C. (1984). "Kiss Me with those Red Lips": Gender and Inversion in Bram Stoker's Dracula. Representations, (8), 107-133. doi:10.2307/2928560

Daymon, C., \& Holloway, I. (2010). Qualitative research methods in public relations and marketing communications. Retrieved from https://ebookcentral.proquest.com

D\&AD. (2015). Case Study: Always \#LikeAGirl. Retrieved December 16, 2017, from https://www.dandad.org/en/d-ad-always-like-a-girl-campaign-case-study-insights/

Fern, E. F. (2001). Advanced focus group research. Thousand Oaks, CA: SAGE. http://dx.doi.org.www.libproxy.wvu.edu/10.4135/9781412990028

Fisher-Buttinger, C., \& Vallaster, C. (2010). Connective branding : building brand equity in a demanding world. Retrieved from https://ebookcentral.proquest.com

Gill, R. (2008). Empowerment/Sexism: Figuring female sexual agency in contemporary advertising. Feminism \& Psychology, 18(1), 35-60.

Goldman, R., Heath, D., \& Smith, S. L. (1991). Commodity feminism. Critical Studies in Mass Communication, 8(3), 333. Retrieved from 
http://search.ebscohost.com/login.aspx?direct=true\&db=ufh\&AN=9334188\&site =ehost-live

Grant, J. (1993). Fundamental feminism: contesting the core concepts of feminist theory. Place of publication not identified: Routledge.

Hains, R. C. (2014). The Significance of Chronology in Commodity Feminism: Audience Interpretations of Girl Power Music. Popular Music \& Society, 37(1), 33-47. doi:10.1080/03007766.2012.726033

Hamel, S. C. (Ed.). (2011). Semiotics: theory and applications. Retrieved from https://ebookcentral.proquest.com

Hekman, S. (2014). The feminine subject. Cambridge, UK: Polity.

Hughes, C. (2002). Key concepts in feminist theory and research. Retrieved from http://ebookcentral.proquest.com/lib/wvu/detail.action?docID=254766

Imondi, B. (2016, January 28). Best Feminist Super Bowl Commercials. Retrieved February 21, 2016, from http://www.aauw.org/2016/01/28/super-bowl-ads/

Jensen, K. (2017). Here We Are Feminism for the Real World. Paw Prints.

Johnston, J., \& Taylor, J. (2008). Feminist consumerism and fat activists: A comparative study of grassroots activism and the dove real beauty campaign. Signs, 33(4), 941-966. doi:10.1086/528849

Joseph, J. (2010). Experience effect: engage your customers with a consistent and memorable brand experience. Retrieved from http://ebookcentral.proquest.com

LaGrone, K. (Ed.). (2009). Alice walkers the color purple. Retrieved from http://ebookcentral.proquest.com

Liamputtong, P. (2011). Focus group methodology: principles and practice. Los Angeles: Sage. http://dx.doi.org/10.4135/9781473957657.n3

Lindström, M. (2012). Brandwashed: tricks companies use to manipulate our minds and persuade us to buy. London: Kogan Page.

Lechte, J. (Ed.). (1994). Fifty key contemporary thinkers: from structuralism to postmodernity. Retrieved from https://ebookcentral.proquest.com/

Mattel. (n.d.). History. Retrieved July 2, 2017, from 


\section{http://www.barbiemedia.com/about-barbie/history.html}

Morgan, D. (1996). Focus Groups. Annual Review of Sociology,22, 129-152. Retrieved from http://www.jstor.org/stable/2083427

Nudd, T. (2015, September 14). Always 'Like a Girl' Adds the 2015 Emmy Award to Its Haul of Trophies. Retrieved Feb 22, 2017, from http://www.adweek.com/brandmarketing/always-girl-adds-2015-emmy-award-its-haul-trophies-166883/

Pardun, C. J. (2013). Advertising and society: An introduction.

Rapp, R. (1988). Is the legacy of second wave feminism post-feminism? Socialist Review, 98, 31-37.

Sanna, E. (2011). Pop monsters: the modern-day craze for vampires and werewolves. Broomall, PA: Mason Crest.

Solomonick, A. (2015). A theory of general semiotics: the science of signs, sign-systems, and semiotic reality. Retrieved from https://ebookcentral.proquest.com/

Stewart, D. W., Shamdasani, P. N., \& Rook, D. W. (2007). Analyzing focus group data. Applied Social Research Methods:Focus groups (pp. 109-133). Thousand Oaks, CA: SAGE Publications Ltd. doi: 10.4135/9781412991841

Stoker, B. (1979). Dracula. New York.

tartecosmetics. (2017, October 2). A quick dry, full coverage, transfer-proofâ $\epsilon_{\mid}^{\prime}$ [Instagram post]. Retrieved from https://www.instagram.com/p/BLqzJp jR0f/?taken-by=tartecosmetics.

Taylor J., Johnston J.,Whitehead K.,. (2016). A corporation in feminist clothing? young women discuss the dove 'Real beauty' campaign. Crit.Sociol.Critical Sociology, 42(1), 123-144.

Tong, R., \& Botts, T. F. (2009). Feminist thought: a more comprehensive introduction (Third ed.). Boulder, CO: Westview Press.

Wimmer, R. D., \& Dominick, J. R. (2014). Mass media research: an introduction (10th ed.). Belmont, CA: Wadsworth Cengage Learning.

Zeisler, Andi. (2016). We were feminists once: From riot grrrl to CoverGirl ${ }^{\circledR}$, the buying and selling of a political movement 
Appendix A: IRB APPROVALLETTER

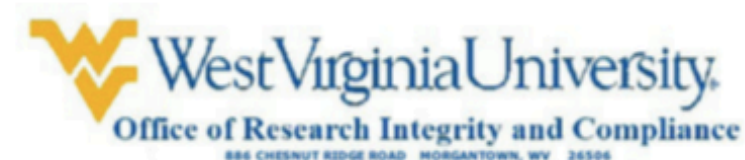

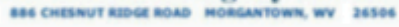

Acknowledgement of Exemption

$10 / 12 / 2017$

To: Stephen Urbanski

From: WVU Office of Research Integrity \& Compliance

Protocol Type: Exempt

Approval Date: 10/12/2017

Submission Type: Initial

Expiration Date: 10/11/2020

Funding: N/A

WVU Protocol \#: 1709753971

Protocol Title: Commodity Feminism Today

The West Virginia University Institutional Review Board has reviewed your submission of Exempt protocol 1709753971. Additional details regarding the review are below:

- This research study was granted an exemption because the Research involves educational tests, survey procedures, interview procedures or observation of public behavior and (i) information obtained is recorded in such a manner that human subjects cannot be identified, directly or through identifiers linked to the subjects; and (ii) any disclosure of the human subjects responses outside the research could not reasonably place the subjects at risk of criminal or civil liability or be damaging to the subjects financial standing, employability, or reputation [45 CFR 46.101(2)]. All exemptions are only good for three years. If this research extends more than three years beyond the approved date, then the researcher will have to request another exemption. The following documents have been acknowledged for use in this study and are available in the WVU+kc system:

The following documents were reviewed and approved for use as part of this submission. Only the documents listed below may be used in the research. Please access and print the files in the Notes \& Attachments section of your approved protocol.

- Moderator's Guide.docx

- Flyer.pdf

Protocol 6: 1709753971 FWA: 00005078 IORG: 0000194
Phone 304-293.7073 Fax: 304-293-3098 Email: IRB बmail.wvuedu 


\section{- Cover Letter Cristina Dans.docx}

\section{WVU IRB acknowledgement of protocol 1709753971 will expire on 10/11/2020.}

If the study is to continue beyond the expiration date, a renewal application must be submitted no later than two (2) weeks prior to expiration date. It is your responsibility to submit your protocol for renewal.

Once you begin your human subjects research, the following regulations apply:

1. Unanticipated or serious adverse events and/or side effects encountered in this research study must be reported to the IRB within five (5) days, using the Notify IRB action in the electronic protocol.

2. Any modifications to the study protocol should be submitted only if there will be an increase in risk to subjects accompanying the proposed change(s).

3. You may not use a modified information sheet until it has been reviewed and acknowledged by the WVU IRB prior to implementation.

The Office of Research Integrity and Compliance will be glad to provide assistance to you throughout the research process. Please feel free to contact us by phone, at 304.293 .7073 or by email at IRB@mail.wvu.edu.

Sincerely,

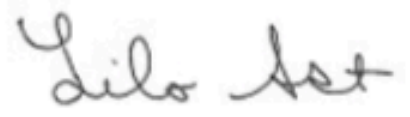

Lilo Ast

Senior Program Coordinator

Protosal A: 1709753971

FWA: 00005078

IORG: 0000194
Phane: 304-293-7073

Fax: 304-293-3098

Email: tRBe rail.wvu.edu 
Appendix B: Focus Group Informed

Consent Statement

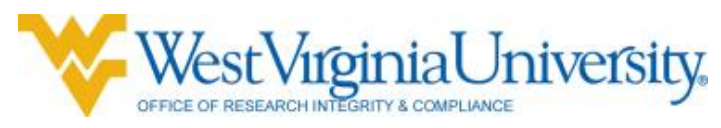

Dear Participant,

This letter is a request for you to take part in a research thesis to assess current thoughts and feelings about an Always \#LikeAGirl commercial video. This thesis is being conducted by Cristina Dans, BA in the Reed College of Media at WVU with supervision of Dr. Stephen J. Urbanski, an associate professor and director of graduate studies in the Reed College of Media, for a Master's Degree in Journalism. Your participation in this thesis is greatly appreciated and will take approximately 45 minutes to participate in the following focus group.

Your involvement in this thesis will be kept as confidential as legally possible. I would like to state that, although I can guarantee confidentiality on my part, I cannot make that same guarantee for participating focus group members. For this reason, I ask that all focus group participants refrain from discussing any portions of the focus group dialog after the focus group has ended. All data will be reported in the aggregate. You must be 18-27 years of age to participate. Other than your first name, which will be replaced with an identifier after the results have been aggregated, I will not ask any information that should lead back to your identity as a participant. Your participation is completely voluntary. You may skip any question that you do not wish to answer and you may discontinue at any time. Your class standing will not be affected if you decide either not to participate or to withdraw. West Virginia University's Institutional Review Board acknowledgement of this thesis is on file.

I hope that you will participate in this research thesis, as it could be beneficial in understanding marketing research tools. Thank you very much for your time. Should you have any questions about this letter or the research thesis, please feel free to contact Cristina Dans at (304) 951-7160 or by email at cmdans@mix.wvu.edu.

Thank you for your time and help with this thesis.

Sincerely,

Cristina Dans

Chestnut Ridge Research Buildin

886 Chestnut Ridge Road

Fax: 304-293-3098 PO Box 6845

http://oric.research.wvu.edu $\quad$ Morgantown, WV 26506-6845 
Appendix C: Flyer

\section{Always \#LikeAGirl Commercial Focus Group Research}

The purpose of this focus group research is to assess current thoughts and feelings about the Always \#LikeAGirl commercial video. If you participate in one of these focus groups, you will receive extra credit in your class. Two focus groups

will be conducted, however, you may not particpate in more than one focus group. This 3 minute and 18 second commercial video will be shown in each

focus group. Focus group discussion will take no more than 45 minutes.

To participate, you must be:

- 18-27 years old

- A student in one or more of the following classes:

JRL 428, JRL 318, JRL 215, JRL 319, JRL 101, JRL 504 and JRL 431 in the Reed College of Media at WVU.

Focus groups will be conducted:

- Monday, November 13 at $5 \mathrm{pm}$

- Wednesday, November 15 at $5 \mathrm{pm}$

This study will be conducted at the WVU Downtown Campus Library, 1549 University Ave, Morgantown, WV 26505. The room number for each focus group will be sent to you if you choose to participate.

Contact Cristina Dans at cmdans@mix.wvu.edu or (304)951-7160 to participate in this study

Principal Investigator: Dr. Stephen Urbanski WVU Reed College of Media

Email: steve.urbanski@mail.wvu.edu

Co-investigator: Cristina Dans WVU Reed College of Media Email:cmdans@mix.wvu.edu
This is an exempt protocol submission.

WVU IRB acknowledgement is on file. WVU IRB approval on file. 


\section{Appendix D: Moderator's Guide}

\section{Facilitator's welcome, introduction and instructions to participants:}

Welcome and thank you for participating in this focus group. You have been asked to participate as your point of view is important. I realize you are busy and I appreciate your time.

Introduction: Read contents of cover letter.

You should try to answer and comment as accurately and truthfully as possible. I and the other focus group participants would appreciate it if you would refrain from discussing the comments of other group members outside the focus group. If there are any questions or discussions that you do not wish to answer or participate in, you do not have to do so; however please try to answer and be as involved as possible.

\section{Ground rules}

- The most important rule is that only one person speaks at a time. There may be a temptation to jump in when someone is talking but please wait until they have finished. Please raise your hand to speak, and state your first name before speaking for transcribing purposes later. For example, "I'm Cristina and I think"

- There are no right or wrong answers

- You do not have to speak in any particular order

- When you do have something to say, please do so. There are many of you in the group and it is important that I obtain the views of each of you

- You do not have to agree with the views of other people in the group

- Does anyone have any questions? (answers).

- OK, let's begin.

Warm up

- First, l'd like everyone to introduce themselves. What is your first name, age and gender (if you wish to address this last question?)

\section{Video}

- Now I will begin this focus group by showing the Always \#LikeAGirl Commercial for you on the screen provided. I will add subtitles to the showing for the clarity of this video. Please remain silent during this portion of the focus group.

\section{Introductory question}

I am just going to give you a couple of minutes to think about your experience with the brand Always. Would each of you share your individual experiences? Please raise your hands.

\section{Main Questions}

- Have any of you seen this video before? Please raise your hands if so.

$\circ$ If so, where did you see it?

- What attitudes/emotions did you feel towards this video?

- What did you like about this video? What parts of the video drove a positive reaction? Please elaborate on your answers.

- What did you dislike about this video? What parts of the video drove a negative reaction? Please elaborate on your answers.

- How did the commercial make you feel about the phrase "Like a girl"?

- What emotions/feelings did it bring up?

- How did the commercial make you feel about the brand Always?

- What emotions/feelings did it bring up?

- What do you think Always is trying to do through this commercial?

- What do you think Always is trying to say/emphasize through this commercial?

- Who do you think Always is speaking to specifically with this commercial?

- What do you think Always is trying to tell this audience? 